DOE/EIA-M063A(95)

\title{
Documentation of the Oil and Gas Supply Module (OGSM)
}

\section{Appendix: Model Developers Report}

July 25, 1994

Prepared by

Energy Information Administration Office of Integrated Analysis and Forecasting Energy Supply and Conversion Division Oil and Gas Analysis Branch

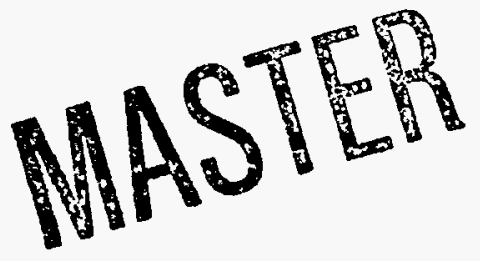


Released for Printing: March 6, 1995

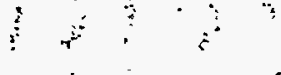




\section{DISCLAIMER}

This report was prepared as an account of work sponsored by an agency of the United States Government. Neither the United States Government nor any agency thereof, nor any of their employees, make any warranty, express or implied, or assumes any legal liability or responsibility for the accuracy, completeness, or usefulness of any information, apparatus, product, or process disclosed, or represents that its use would not infringe privately owned rights. Reference herein to any specific commercial product, process, or service by trade name, trademark, manulacturer, or otherwise does not necessarily constitute or imply its endorsement, recommendation, or favoring by the United States Government or any agency thereof. The views and opinions of authors expressed herein do not necessarily state or reflect those of the United States Government or any agency thereof. 


\section{DISCLAIMER}

Portions of this document may be illegible in electronic image products. Images are produced from the best available original document. 


\section{Introduction}

The Office of Integrated Analysis and Forecasting (OIAF) is required to provide complete model documentation to meet the EIA Model Acceptance Standards. The Documentation for the Oil . and Gas Supply Module (OGSM) provides a complete description of the OGSM methodology, structure, and relation to other modules in the National Energy Modeling System (NEMS). This Model Developers Report (MDR) serves as an appendix to the methodology documentation. This report provides an overview of the model and an assessment of the sensitivity of OGSM results to changes in input data or parameters.

The Oil and Gas Supply Module (OGSM) consists of a set of submodules (Figure 1) that perform supply analysis regarding domestic oil and gas production and foreign trade in natural gas between the United States and other countries via pipeline or as liquefied natural gas (LNG). The OGSM provides parameter estimates representing crude oil and natural gas supplies by selected fuel types on a regional basis to support the market equilibrium determination conducted within other modules of the National Energy Modeling System (NEMS). In this equilibration, the oil and gas supplies in each period are balanced against regional derived demands for the produced fuels. A simultaneous solution of demand and supply produces the market-clearing prices and quantities in the disjoint wellhead and enduse markets. The description of the market analysis models may be found in the separate methodology documentation reports for the Petroleum Market Module (PMM) and the Natural Gas Transmission and Distribution Model (NGTDM).

Figure 1. Submodules within the Oil and Gas Supply Module

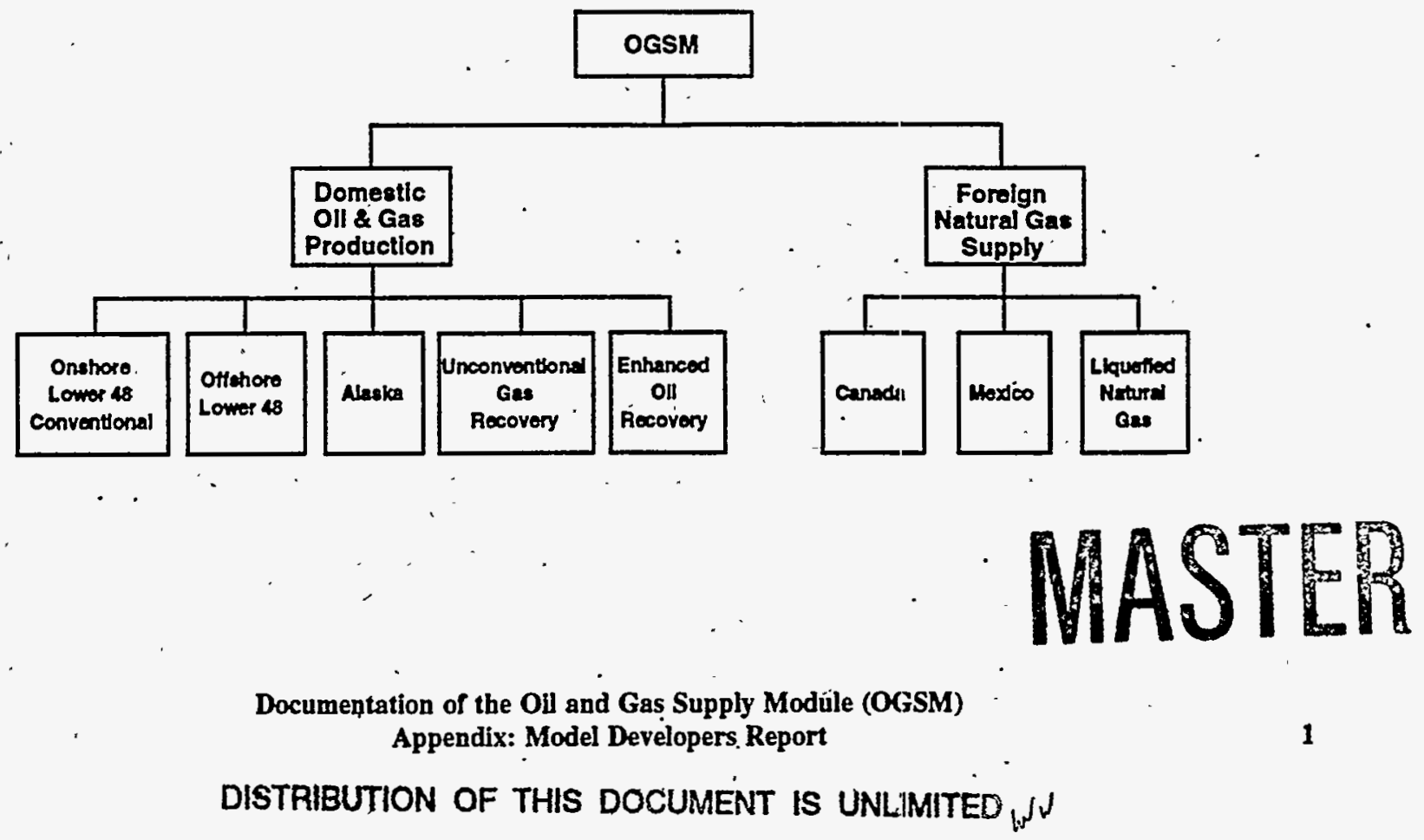


- The OGSM mirrors the activity of numerous firms that produce oil and natural gas from domestic fields throughout the United States, acquire natural gas from foreign producers for resale in the United States, or sell U.S. gas to foreign consumers. The OGSM encompasses domestic crude oil and natural gas supply by both conventional and nonconventional recovery techniques. Nonconventional recovery includes enhanced oil recovery (EOR), and unconventional gas recovery (UGR) from tight gas formations, Devonian shale and coalbeds. Crude oil and natural gas projections are further disaggregated by geographic region. The OGSM represents foreign trade in natural gas as imports and exports at U.S. border crossing points. These foreign transactions may occur via pipeline (Canada or Mexico) or via ships transported as LNG.

The OGSM includes an enhanced methodology for estimating short-term oil and gaś supply functions. Short-term is defined as a one-year period in the OGSM. This enhancement improves the procedure for equilibrating natural gas and oil markets by allowing the PMM and NGTDM to determine regional market-clearing prices for each fuel. The previous modeling system equilibrated markets only at a national market-clearing price.

Output prices have both a short-term and long-term influence on oil and gas supplies in the OGSM. These two effects are distinctly different. The short-term impact occurs within the annual market equilibration of the PMM and NGTDM, in which quantities supplied respond to the market price in that period. The market price in each period affects the investments required for subsequent production of oil and gas, and hence, it influences longer-term supply.

The analytical approach in the MDR relies on one-at-a-time sensitivity analysis. The sensitivity assessment focuses on selected major outputs of OGSM, as they are affected by variation in selected major inputs. This approach provides a straightforward analysis approach to assess the performance characteristics of OGSM.

The present MDR analysis focuses on OGSM's simulation of domestic oil and gas supply and - excludes OGSM's simulation of foreign natural gas supply. The exclusion of gas imports from the MDR analysis is warranted for several reasons. The Annual Energy Outlook 1994 (AEO94) included foreign 'gas imports as an exogenous input to the AEO94. Differences in gas import volumes in an OGSM standalone run would not affect other OGSM results (e.g., gas or oil production or prices). The absence of change in the results for a standalone run, based on variation in gas imports, would not constitute meaningful analysis.

The MDR analysis is based on standalone Oil and Gas Supply Module (OGSM) runs, not integrated National Energy Modeling System (NEMS) runs. Reliance on standalone runs has two 
implications for the analysis resu's.s. First, production estimates are expected to differ slightly between integrated and standalone runs. Additionally, the present analysis assesses the sensitivity of the nonassociated (NA) gas estimates, ${ }^{1}$ but it does not include associated-dissolved (AD) gas. ${ }^{2}$.

The OGSM in an integrated NEMS run provides estimates of oil and gas supply for use in determining market-clearing prices and quantities for oil and natural gas at the wellhead. Oil and gas supply in this context refers to a range of possible production volumes corresponding to a range of prices. These supply parameters can be used in a standalone run to provide estimates of production outside the market equilibration process.

The OGSM supply function for an integrated run is defined with respect to a 'target' production level that equals the product of the production-to-reserves ratio and the reserves. This volume has an associated base f.ice at which the volume will be produced. The target volume subsequently is adjusted in the equilibration procedure to reflect the difference between the equilibrium price and the base price. The reported production in an OGSM standalone run is the target production level. This value is generally quite close to the equilibrium quantity of an. integrated run since the short-term supply function is highly inelastic.

Changes in factors directly affecting gas supply impact NA gas activities. $\mathrm{AD}$ gas is the coproduct produced with crude oil. $\mathrm{AD}$ gas supply generally is quite unresponsive to market conditions exicept for those factors influencing the recovery of crude oil. The $\mathrm{AD}$ gas volumes are determined in the NGTDM as a coproduct of the crude oil production estimates passed from the PMM. Thus, endogenous values for AD gas are not available in an OGSM standalone run since these values are estimated outside the OGSM.

The Reference Case for this analysis is the set of standalone run results that are based on the Reference Case input data and assumptions for the Annual Energy Outlook 1994 (AEO94). Projection estimates in the MDR Reference Case vary slightly from those of the AEO94. The basic data and parameters are those from the AEO, but the data that would be endogenously determined within an integrated model run, such as wellhead prices, do not necessarily match the actual AEO prices for each category and region. Further, some alterations to the implemented methodology were introduced in OGSM to allow the sensitivity testing. The impact of the modified implementation on the model results is expected to be insignificant.

\footnotetext{
'Nonassociated natural gas is natural gas not in contact with significant quantities of crude oil in a reservoir.

${ }^{2}$ Associated-dissolved gas is the combined volume of natural gas that occurs in crude oil reservoirs either as free gas (associated) or as gas in solution with crude oil (dissolved).
} 
These differences result in small discrepancies between the Reference Case estimates in each study. For example, crude oil production in 2010' varies by less than 2 percent, 'while natural gas production differs by less than 0.1 percent.

The next section of this report provides a discussion of important properties of the OGSM. This is followed by a presentation of the testing procedure and the results. The section discusses the selection of input variables, their relative variation, and criteria for test design. A Reference Case, based on the AEO94, is established for the analysis. ${ }^{3}$. The results showing the model sensitivity indicated by the difference between the test results and those of the Reference Case are presented and discussed with respect to the characteristics of the OGSM and its relation to the industry. The report concludes with a discussion of the sensitivities, including a discussion of their correspondence with industry experience.

3The correspondence between the AEO94 Reference Case and the MDR Reference Case is close, but not exach, as discussed subsequently in the beginning of Chapter IV. Hereafter within this report, Reference Case refers to the standalone version developed for the MDR. 


\section{Properties of the OGSM}

\section{Solution Methodology}

The solution methodology to the Oil and Gas Supply Module (OGSM) of the National Energy Modeling System (NEMS) comprises a sequence of computations using linear and non-linear equations to develop the OGSM oil and gas supply function parameters. ${ }^{4}$ Consequently, convergence within the OGSM is not a relevant issue since the OGSIM algorithm is not iterative.

The current-period production and the corresponding price are not determined within OGSM in , an integrated NEMS run. The OGSM provides current-year supply parameters to other NEMS modules for use in solving for equilibrium wellhead prices and quantities. The supply parameters are the proved oil and gas reserves, the production-to-reserves ratio, and the supply price elasticity coefficient. Estimates of the current-period fuel prices and economic conditions influence the OGSM drilling investment decisions, and hence supply capacity, by adding proved reserves and altering the production-to-reserves ratio.' Estimates for reserves and the productionto-reserves ratio in period $t$ are those determined at the end of period $t-1$. Hence, the supply parameters depend only on the values within NEMS during the previous year, and so they are not factors that are incorporated into the iterative solution procedures employed elsewhere in NEMS.

\section{Theoretical Considerations ,}

\section{Domain of Module Solution}

Rigorous tests have not been performed to determine the maximal ranges and input interdependencies over which the model results remain valid. Nonetheless, the Model Developers Report (MDR) analysis, based on shifts in the selected input variables, provides an indication of ranges for which the model has proven to be valid. It must be stressed that care must be exercised in selecting the proper range, especially with inputs that are correlated, so that the model produces feasible outputs.

The interested reader can find a more complete description of the OGSM in the previously published methodology documentation report. 
The model must produce a unique solution in the domain of applicability of the model (that is; when "reasonable and consistent inputs" are provided into the model). This conclusion is based on the direct (rather then iterative) solution algorithm.

Existence and convergence are not issues relevant to the OGSM. If inconsistent pairs of such inputs or negative prices are chosen, however, the model may produce nonsensical results. Whether the model is run in an integrated or standalone fashion, it is the responsibility of the user-analyst to be certain that the inputs are consistent and credible. The following examples illustrate types of assumptions that may produce model results that are questionable or worse.

-Input values that differ markedly from historical or typical values will produce results that need careful scrutiny. For example, extraordinarily high (low) oil or gas prices may lead to unacceptably high drilling levels. ${ }^{5}$

- Unlikely combinations of input values should be considered carefully. For example, exceedingly high (low) oil prices and low (high) gas prices in the same scenario may produce counterintuitive results; e.g., high oil prices motivate additional associated-dissolved gas production, perhaps to the point of offsetting the decline in nonassociated gas.

- Unduly high extraction rates for new reserve additions will cause aggregate production volumes to be unacceptably low relative to the stock of proved reserves.

\section{Model Stability}

Given the OGSM structure and the "typical inputs" from other parts of NEMS, an assessment of the available evidence suggests that the OGSM results are consistent with historical trends and other model forecasts. Sensitivity runs discussed in later sections of this report provide an illustration of the behavior of the model. These runs illustrate how the model behaves with respect to the six most important inputs to the model.

\footnotetext{
SThe prior specification of "acceptable" ranges for output or input variables. is an attractive notion, but likely futile exercise. Achieving the necessary agreement required for such an exercise would be very difficult, if at all possible, especially if one were to account for the set of conditions under which the range is itself valid. Fortunately, providing this guideline is not necessary. The prudent analyst would naturally exercise caution in the use of any model and the interpretation of its results.
} 


\section{Methodology}

\section{Analysis Approach}

This report focuses on the responsiveness of selected output variables of the Oil and Gas Supply Module (OGSM), due to changes in certain key input variables. The analysis proceeds on the basis of one-at-a-time modifications to the input variables. This sensitivity analysis approach, while limited in certain aspects, does meet the principal intent of the Model Developers Report (MDR): to assess the performance characteristics of the OGSM.

The analysis shows the impact of input variation on key output variables: production, reserves, and drilling. This report presents the sensitivity analysis results for the aggregate estimates of the following variables.

Crude oil production

Crude oil reserves

- Natural gas production

-Natural gas reserves

-Total wells

-Oil wells

Gas wells

-Dry holes

Other variables (for example, aggregate production-to-reserves ratios and remaining economically recoverable resources in each period) undoubtedly would be of interest to certain analysts, but the chosen variables were selected as those that generally are of primary interest to the largest segment of the analytical community.

The analysis is presented in the next chapter of this report. The remainder of this chapter discusses the selected input variables and the test design. 


\section{Input Variables}

The version of the OGSM that was used in support of the Annual Energy Outlook 1994 (AEO94) is an abbreviated form of the planned methodology described in the earlier Component Design Reports. This version of the module does not have as many key input variables as intended, but the current version of OGSM still provides the opportunity to analyze the sensitivity of the most interesting non-tax input data and parameters. The selected input variables for the MDR analysis include:

Economically recoverable oil and gas resource estimates

-Technology development and penetration rates

Extraction rates for new proved reserve additions

-Oil and gas wellhead prices

-Drilling costs

Drilling response parameters

The first three variables affect the results from the physical process portion of the model. Changes to the resource estimates and technology factors alter the resource productivity of exploratory and developmental drilling. Technology also impacts drilling costs, and thus, the number of well completions. The extraction rate parameters represent the expected production potential of the new proved reserve additions. The last three variables, along with technology, affect the level of drilling, which in turn alters the reserve stock and production potential in any projection yèr.

The sensitivity tests are conducted for pairs of experimental runs, in which each input variable shifts to alternate higher or lower input values. The rationale for the test design includes the criteria for selecting the variable and determining the magnitude of the variable shift. The following scheme for varying the input variables was adopted for the analysis.

\section{-Economically recoverable resource estimates}

The OGSM receives the regional estimates for economically recoverable oil and gas resources by category as fixed values. In fact, these resource estimates are quite uncertain. They actually constitute point estimates selected from the range of possible values along an explicit or implied probability distribution. The Low and High Recovery test scenarios reflect the inherent uncertainty surrounding recoverable resource estimates. . 
Economically recoverable resource estimates in the Reference Case are those from the AEO94. The Low and High Recovery tests employ a systematic decrease or increase in recoverable resources across each recovery category in the resource depiction. The Low and High Recovery estimates within each resource category (for example, conventional oil, or shallow or deep conventional gas) are adjusted by the proportional factors that were cleveloped for the Low/High Recovery cases in the Annual Energy Outlook 1993 (AEO93). The resource estimates are drawn from this work because most published recoverable resource estimates do not include a depiction of the uncertainty associated with volumetric estimates.

The change in resources is not uniform for all regions or categories. The low recovery values by region or category range between 23 to 30 percent reductions and 29 to 71 percent increases in the high set of values. (The wide differences in the values of the high test reflect the skewed distributions associated with resource estimates.) The economically recoverable resource estimates for the Low Recovery, Reference, and High Recovery tests are shown in Tables 1A and $1 B$.

\begin{tabular}{|c|c|c|c|c|c|c|c|c|}
\hline \multirow{3}{*}{ 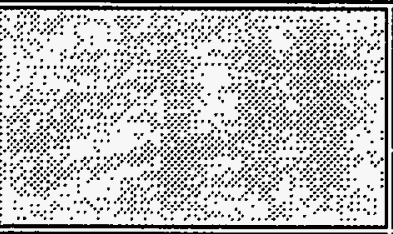 } & \multirow{2}{*}{\multicolumn{2}{|c|}{$\begin{array}{c}\text { Low } \\
\text { Recovery } \\
\text { Resource }\end{array}$}} & \multirow{2}{*}{\multicolumn{2}{|c|}{$\begin{array}{l}\text { Reference } \\
\text { Resource }\end{array}$}} & \multirow{2}{*}{\multicolumn{2}{|c|}{$\begin{array}{c}\text { High } \\
\text { Recovery } \\
\text { Resource }\end{array}$}} & \multicolumn{2}{|c|}{ \% Difference } \\
\hline & & & & & & & \multirow{2}{*}{$\begin{array}{c}\text { Low } \\
\text { Recovery } \\
\text { versus } \\
\text { Reference }\end{array}$} & \multirow{2}{*}{$\begin{array}{c}\text { High } \\
\text { Recovery } \\
\text { versus } \\
\text { Reference } \\
\end{array}$} \\
\hline & 1990 & 2010 & 1990 & 2010 & 1990 & 2010 & & \\
\hline Total U.S. Unproved & 57.99 & 86.17 & 80.89 & 120.19 & 120.03 & 178.35 & $-28.3 \%$ & $48.4 \%$ \\
\hline Lower 48 States & 50.61 & 75.20 & 70.36 & 104.55 & 104.71 & 155.59 & $-28.1 \%$ & $48.8 \%$ \\
\hline Undiscovered & 30.60 & 45.48 & 43.53 & 64.68 & 63.03 & 93.66 & $-29.7 \%$ & $44.8 \%$ \\
\hline Onshore & 23.81 & 35.38 & 33.53 & 49.83 & 45.94 & 68.26 & $-29.0 \%$ & $37.0 \%$ \\
\hline Offshore & 6.80 & 10.10 & 10.00 & 14.85 & 17.09 & 25.40 & $-32.0 \%$ & $71.0 \%$ \\
\hline Inferred Reserves & 20.00 & 29.72 & 26.83 & 39.87 & 41.68 & 61.93 & $-25.4 \%$ & $\overline{55.3 \%}$ \\
\hline EOR & 4.51 & 6.70 & 6.17 & 9.17 & 8.31 & 12.35 & $-26.9 \%$ & $34.7 \%$ \\
\hline Other Onshore & 13.37 & 19.87 & 17.83 & 26.50 & 29.06 & 43.19 & $-25.0 \%$ & $63.0 \%$ \\
\hline Offshore & 2.12 & 3.15 & 2.83 & 4.20 & 4.30 & 6.39 & $-25.0 \%$ & $52.0 \%$ \\
\hline Alaska & 7.39 & 10.98 & 10.53 & 15.65 & 15.32 & 22.77 & $-29.8 \%$ & $45.5 \%$ \\
\hline Proved Reserves & 26.25 & 26.25 & 26.25 & 26.25 & 26.25 & 25.25 & $0.0 \%$ & $0.0 \%$ \\
\hline Total Crude Oil & 84.24 & 112.42 & 107.14 & 146.44 & 146.28 & 20.4 .60 & $-21.4 \%$ & $36.5 \%$ \\
\hline
\end{tabular}




\begin{tabular}{|c|c|c|c|c|c|c|c|c|}
\hline \multirow{3}{*}{ 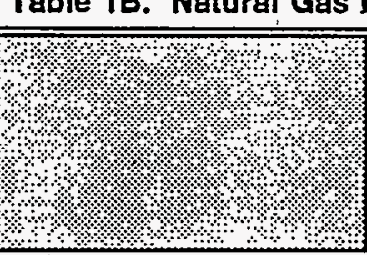 } & \multirow{2}{*}{\multicolumn{2}{|c|}{$\begin{array}{l}\text { Low } \\
\text { Recovery } \\
\text { Resource }\end{array}$}} & \multirow{2}{*}{\multicolumn{2}{|c|}{$\begin{array}{l}\text { Reference } \\
\text { Resource }\end{array}$}} & \multirow{2}{*}{\multicolumn{2}{|c|}{$\begin{array}{c}\text { High } \\
\text { Recovery } \\
\text { Resource }\end{array}$}} & \multicolumn{2}{|c|}{$\%$ Difference } \\
\hline & & & & & & & \multirow{2}{*}{$\begin{array}{c}\text { Low } \\
\text { Recovery } \\
\text { versus } \\
\text { Reference }\end{array}$} & \multirow{2}{*}{$\begin{array}{c}\text { High } \\
\text { Recovery } \\
\text { versus } \\
\text { Reference }\end{array}$} \\
\hline & 1990 & 2010 & 1990 & 2010 & 1990 & 2010 & & \\
\hline Total U.S. Unproved & 648.97 & 964.33 & 851.88 & 1265.84 & 1132.59 & 1682.97 & $-23.8 \%$ & $33.0 \%$ \\
\hline Lower 48 States & 625.60 & 929.61 & 818.57 & 1216.34 & 1084.13 & 1610.95 & $-23.6 \%$ & $32.4 \%$ \\
\hline Undiscovered & 273.38 & 406.24 & 356.63 & 529.93 & 467.38 & 694.50 & $-23.3 \%$ & $31.1 \%$ \\
\hline Onshore & 180.59 & 268.34 & 234.53 & 348.50 & 302.54 & 449.56 & $-23.0 \%$ & $29.0 \%$ \\
\hline Offshore & 92.80 & 137.89 & 122.10 & 181.44 & 164.84 & 244.94 & $-24.0 \%$ & $35.0 \%$ \\
\hline Inferred Reserves & 111.58 & 165.79 & 145.30 & 215.91 & 189.30 & 281.28 & $-23.2 \%$ & $30.3 \%$ \\
\hline Other Onshore & 88.10 & 130.91 & 114.42 & 170.02 & 147.60 & 219.32 & $-23.0 \%$ & $29.0 \%$ \\
\hline Offshore & 23.47 & 34.88 & 30.89 & 45.90 & 41.70 & 61.96 & $-24.0 \%$ & $35.0 \%$ \\
\hline Unconventional & .240 .64 & 357.58 & 316.63 & 470.50 & 427.45 & 635.17 & $-24.0 \%$ & $35.0 \%$ \\
\hline Tight Gas & 176.62 & 262.45 & 232.40 & 345.33 & 313.74 & 466.20 & $-24.0 \%$ & $35.0 \%$ \\
\hline Devonian Shale & 16.13 & 23.98 & 21.23 & 31.55 & 28.66 & 42.59 & $-24.0 \%$ & $35.0 \%$ \\
\hline Coalbed Methane & 47.88 & 71.15 & 63.00 & 93.61 & 85.05 & 126.38 & $-24.0 \%$ & $35.0 \%$ \\
\hline Alaska & 23.37 & 34.72 & 33.31 & 49.50 & 48.46 & 72.02 & $-29.8 \%$ & $45.5 \%$ \\
\hline Proved Reserves & 169.35 & .169 .35 & 169.35 & 169.35 & 169.35 & 169.35 & $0.0 \%$ & $0.0 \%$ \\
\hline Total Natural Gas & 818.32 & 1133.68 & 1021.23 & 1435.19 & 1301.94 & 1852.32 & $-19.9 \%$ & $27.5 \%$ \\
\hline
\end{tabular}

Variation in the degree of adjustment to the resource estimates by region or category is important. The projected values for production and reserves in the resultant outlook do not depend solely on the total volume. An important aspect of any aggregate resource estimate is the decomposition of the total among regions and categories. For example, an aggregate resource volume can result in widely different outlooks depending on the distribution of oil or gas between higher or lower cost categories or regions.

\section{-Technology progress factors}

Technology in the model operates in two ways: expanding the volume of economically recoverable resources and lowering drilling costs per well. The rate of technological progress reflects the benefits from the combined effects of both technological development and industry penetration (that is, adoption of the technological improvements by firms). The impact of technological change in the industry is debated widely. The technology progress values affecting both resources and drilling costs were established with respect to published estimates in the literature. The technology expansion assumption affecting the resource base in the Annual Energy Outlook 1994 (AEO94) is an across the board rate of 2 percent per year. Technology. factors reducing drilling costs vary by fuel category and region. These factors reflect the working assumption that relatively high cost endeavors or activities in frontier regions have the most 
potential for improvement. Drilling costs in the onshore Lower $48^{\circ}$ states are assumed to decline annually by 1 percent for conventional oil and shallow gas drilling, and 2 percent for deep gas . and unconventional gas recovery (UGR). Technology lowers offshore drilling costs by 3 percent per year. For the purposes of this MDR analysis, technological progress rates were adjusted proportionately by \pm 50 percent from the Reference Case values, yielding alternate annual rates that vary widely from the $A E O 94$ values. The use of such a relatively broad range for the technology factors conforms roughly to the diversity in opinion in the professional literature on this subject.

\section{-Extraction rates}

New reserve additions in OGSM produce oil and gas at rates that vary by region and category. The rates for new reserve additions are slightly higher than those for the base year stock, reflecting an assumption of improved development techniques employed for new projects. This rate for incremental reserves is averaged into the overall production-to-reserves ratio for each fuel by region and category. The revised average ratio then is employed as the extraction rate for the combined stock of prior and new reserves combined. This weighted average extraction rate asymptotically approaches the assumed rate for new reserve additions as the proportion of reserves added during the projection periods increases. The new reserve additions extraction rate is varied by \pm 10 percent in the MDR analysis.

\section{-Oil and gas prices}

Domestic oil and gas production supply potential in any year depends greatly on the assumed oil and gas price paths through all preceding periods. The widest spread on crude oil and natural gas prices in the AEO94 occurred in the World Oil Price (WOP) and Economic Growth scenarios, respectively. This MDR sensitivity analysis combines the oil prices from the High (Low) WOP case and the natural gas prices from the High (Low) Economic Growth case in alternate high/low wellhead price scenarios to produce test results based on a wider price range than those of any single scenario in the AEO94.

\section{-Drilling costs}

Drilling costs are subject to errors in measurement. The MDR analysis shifts drilling costs \pm 20 percent. This value for the proportionate adjustment, while arbitrary, was selected because the changes in costs significantly alters the projected number of new wells completed in all categories. 


\section{-Drilling response parameters}

The AEO94 analysis depended on an ad hoc algorithm to determine the projected levels of drilling as a function of price. The base level of drilling in each period is adjusted by the ratio of the current wellhead price to a user specified scale factor. ${ }^{6}$ This ratio is raised to a user specified power, which is the drilling response factor. This simple algorithm utilizes two parameters: the drilling response factor, and the scale factor. The values of each parameter. depend upon analyst judgement. The low/high variation analysis is based on varying the drilling response parameters by \pm 10 percent.

${ }^{6}$ Additional details on this methodology are provided in the documentation cited previously. 


\section{IV: Sensitivity Results}

\section{Introduction}

The results from each test are presented in a series of tables and a set of graphs. The tables are used to show the impact of the input change in each test as it affects the output variables. The graphs provide a useful basis for comparing the impact on a selected output variable as it is affected by each test change in turn.

There are six sets of tables, one for each input variable test. Each table contains the 2000 and 2010 results in a set of three displays, designated A, B, and C. The A table shows the levels for each output variable. The $\mathrm{B}$ table shows the percentage change between the test result and the Reference Case. Lastly; the $\mathrm{C}$ table presents the ratio of the percentage change in output to the percentage change in the input variable as an indication of the relative sensitivity of the model.

The five sets of graphs ( 2 graphs per set) exhibit the percentage difference between the test results and the Reference Case for each of the five output variables: oil production, oil reserves, NA gas production, NA gas reserves, and total wells. The differences in these graphs show the impact of each change as a function of time. Oil, gas, and dry well completions are not shown individually. There are two graphs in each set, each with the results from three tests. This disaggregated presentation is intended to avoid obscuring the results, which is likely if all test results were crowded into a single graph.

\section{Input Variable Tést Results}

\section{Economically Recoverable Resources}

This test case assesses the impact of variation in the initial economically recoverable oil and gas resource estimates. Both production and reserves estimates increase (decrease) in the High (Low) Recovery test, as expected (Table 2.A). Drilling does not vary from. Reference Case levels because the determinants of drilling in the current version of the OGSM-prices and costs-do not vary between the tests. Closer inspection of the results yields some additional insights into the model.

Production and reserves estimates vary almost symmetrically between the Low Recovery and High Recovery tests (Table 2.B). This characteristic of the output undoubtedly relates to the use 


\begin{tabular}{|c|c|c|c|c|c|c|c|}
\hline \multicolumn{8}{|c|}{$\begin{array}{c}\text { Table 2.A Sensitivity Analysis: Variation in Economically Recoverable Resource Case } \\
\text { (Oil=-24\% or }+33 \% \text {; Gas }=-29 \% \text { or }+51 \% \text { ) }\end{array}$} \\
\hline \multicolumn{2}{|c|}{ ४ै। } & \multicolumn{3}{|c|}{2000} & \multicolumn{3}{|c|}{2010} \\
\hline Output Variable & Units & $\begin{array}{l}\text { Low } \\
\text { Case }\end{array}$ & $\begin{array}{c}\text { Reférence } \\
\text { Case }\end{array}$ & $\begin{array}{l}\text { High } \\
\text { Case }\end{array}$ & $\begin{array}{l}\text { Low } \\
\text { Case }\end{array}$ & $\begin{array}{c}\text { Referenice } \\
\text { Case }\end{array}$ & $\begin{array}{l}\text { High } \\
\text { Case }\end{array}$ \\
\hline Oil Production & $M B / D$ & $4,888^{\circ}$ & 5,142 & 5,429 & 4,272 & 4,893 & 5,701 \\
\hline Oil Reserves & $B B$ & 17.54 & 18.86 & 20.19 & 14.09 & 17.14 & 20.43 \\
\hline Gas'Production & TCF/Y & 13.93 & 14.83 & 15.74 & 13.37 & 15.21 & 17.22 \\
\hline Gas Reserves & TCF & 130.02 & 139.19 & 148.80 & 121.89 & 138.85 & 157.65 \\
\hline Total Wells & Wells & 50,311 & $50,31.1$ & 50,311 & 79,571 & 79,571 & 79,571 \\
\hline Oil Wells & Wells & 18,076 & 18,076 & 18,076 & 26,906 . & 26,906 & 26,906 \\
\hline Gas Wells & Wells & 19,858 & 19,858 & 19,858 & 33,436 & 33,436 & 33,436 \\
\hline - Dry Holes & Wells & 12,377 & 12,377 & 12,377 & 19,228 & 19,228 & 19,228 \\
\hline
\end{tabular}

of a fixed set of wellhead prices. The use of an integrated run for these tests would have recognized the demand and supply interactions, which induce a revised set of prices, leading to altered drilling, reserves, and production. The fixed prices in this test, given no change to costs, do not allow variation in drilling.

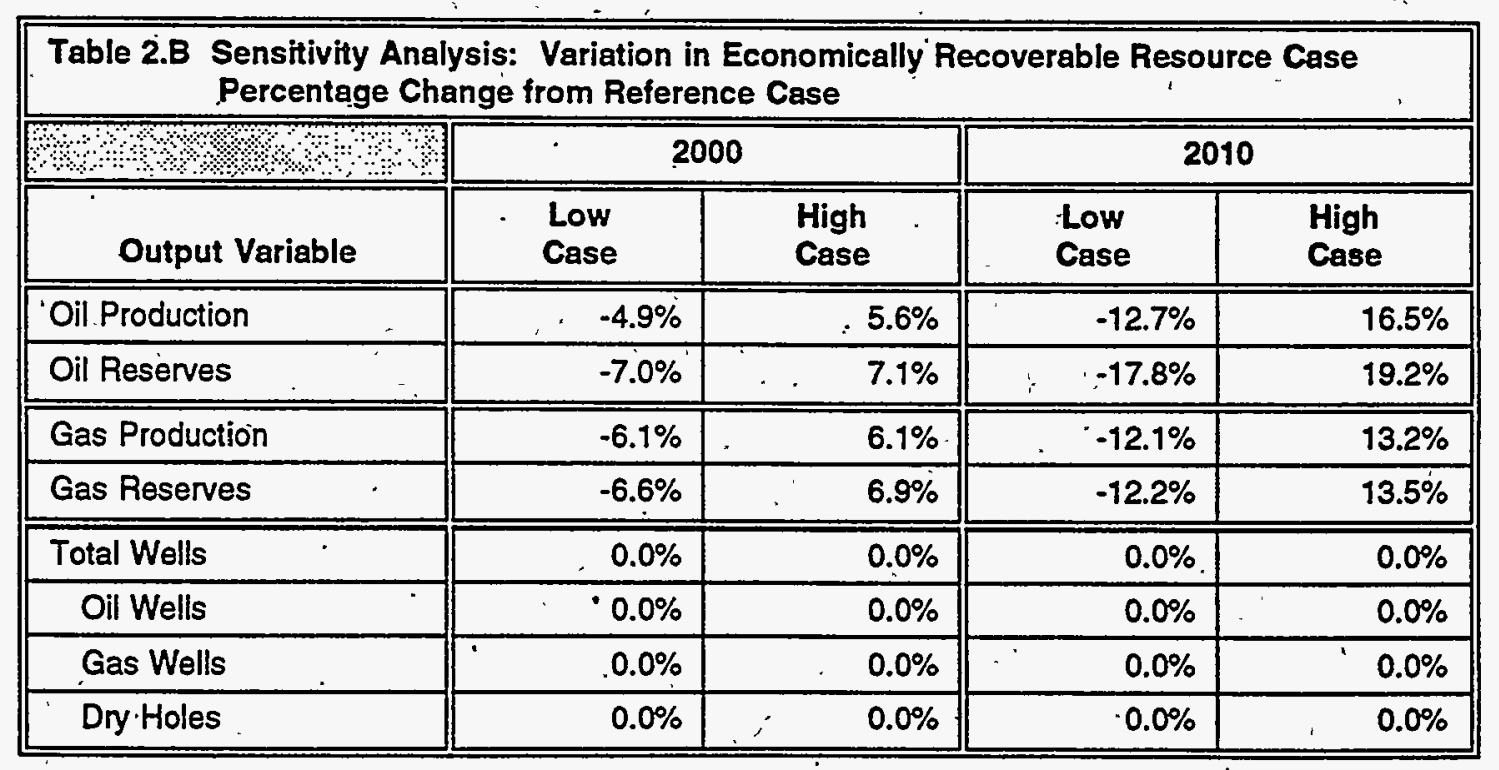

The impact of the changes to the economically recoverable resources has a cumulative impact on the results. While the changes are almost symmetric around the Reference Case, the differences between the tests do increase with time. The greatest change from the Reference Case occurs in the High Recovery test (Table 2.B). This is attributable to the size of the 
percentage increase in the resource estimates for the High Recovery test, which exceeds the percentage decrease in the Low Recovery test.

When adjusted for the relative size of the change in the aggregate resource estimates, the impact of the Low Recovery assumptions is stronger (Table 2.C). This result suggests that the effects from depletion of a smaller resource estimate appear more strongly than the benefits of higher production and reserves with a larger resource estimate. The recoverable resource in the High Recovery' test reduces the inevitable rate of resource exhaustion from what it otherwise would be in either the Reference Case or the Low Recovery Test. This observation may not be valid if the length of the projection period were itself to vary.

\begin{tabular}{|c|c|c|c|c|}
\hline \%४४ ४ ২ & & & 20 & \\
\hline Output Variable & $\begin{array}{l}\text { Low } \\
\text { Case }\end{array}$ & $\begin{array}{l}\text { High } \\
\text { Case }\end{array}$ & $\begin{array}{l}\text { Low } \\
\text { Case }\end{array}$ & $\begin{array}{l}\text { High } \\
\text { Case }\end{array}$ \\
\hline Oil Production & 0.21 & 0.17 & 0.53 & 0.50 \\
\hline Oil Reserves & 0.29 & 0.21 & 0.75 & -0.58 \\
\hline Gas Production & 0.21 & 0.12 & 0.42 & 0.26 \\
\hline Gas Reserves & 0.23 & 0.14 & 0.43 & 0.27 \\
\hline Total Wells & $N / A^{*}$ & $\mathrm{~N}^{\mathrm{A}} \mathrm{A}^{*}$ & $N / A^{*}$ & $\mathrm{NA}^{*}$ \\
\hline Oil Wells & 0.00 & 0.00 & 0.00 & 0.00 \\
\hline Gas Wells & 0.00 & 0.00 & 0.00 & 0.00 \\
\hline Dry Holes & $N / A^{*}$ & $N / A^{*}$ & $N / A^{*}$ & $\mathrm{~N}^{*}$ \\
\hline
\end{tabular}

N/A*: The 'Total Wells' and 'Dry Holes' categories are excluded from fuel-specific computations because these categories combine oil and gas activities.

\section{Technological Progress Factors}

Technology operates to expand the economically recoverable oil and gas resource estimates and reduce the effective drilling costs. This dual impact manifests itself in the model results in the High Technology test as higher drilling productivity and more well completions. The converse is true for the Low Technology test. The drilling increase leads to more production and a larger reserves stock in each year (Table 3.A).

The impact of the technology factors increases with time. The growing cumulative impact is similar to that of the economically recóverable resource tests. Technology also has a roughly. symmetric impact, although the impact differs on the individual output variables. For example, 


\begin{tabular}{|c|c|c|c|c|c|c|c|}
\hline \multicolumn{8}{|c|}{$\begin{array}{l}\text { Table 3.A Sensitivity Analysis: Variation in Technological Progress Rate } \\
\quad(-50 \% \text { or }+50 \%)\end{array}$} \\
\hline \multicolumn{2}{|c|}{ \%० } & \multicolumn{3}{|c|}{2000} & \multicolumn{3}{|c|}{2010} \\
\hline Output Variable & Units & $\begin{array}{l}\text { Low } \\
\text { Case } \\
\end{array}$ & $\begin{array}{c}\text { Reference } \\
\text { Case }\end{array}$ & $\begin{array}{l}\text { High } \\
\text { Case } \\
\end{array}$ & $\begin{array}{l}\text { Low } \\
\text { Case }\end{array}$ & $\begin{array}{c}\text { Reference } \\
\text { Case }\end{array}$ & $\begin{array}{l}\text { High } \\
\text { Case }\end{array}$ \\
\hline Oil Production & $M B / D$ & 5,047 & 5,142 & 5,271 & 4,422 & 4,893 & 5,373 \\
\hline Oil Reserves & $\mathrm{BB}$ & 18.72 & 18.86 & 19.12 & 15.82 & 17.14 & 18.65 \\
\hline Gas Production & TCF/Y & 14.55 & 14.83 & 15.12 & 13.92 & 15.21 & 16.69 \\
\hline Gas Reserves & TCF & 136.25 & 139.19 & 142.28 & 127.57 & 138.85 & 151.66 \\
\hline Total Wells & Wells & 48,112 & 50,311 & 52,644 & 71,146 & 79,571 & $.89,258$ \\
\hline Oil Wells & Wells & 17,435 & 18,076 & 18,746 & 24,609 & 26,906 & 29,449 \\
\hline Gas Wells & Wells & 18,789 & 19,858 & 21,006 & 29,158 & 33,436 & 38,476 \\
\hline Dry Holes & Wells & 11,887 & 12,377 & 12,892 & 17,378 & 19,228 & 21,333 \\
\hline
\end{tabular}

the High Technology assumption reduces drilling costs, thereby increasing well completions of all well types. Additional drilling and a higher rate of reserve additions per well cause reserves to increase; 8.8 percent for oil reserves, and 9.2 percent for gas reserves in 2010 (Table 3.B). The higher average extraction rate, in conjunction with the increased reserves relative to the Reference Case, leads to larger increases in production; 9.0 percent for both oil and gas in 2010.

\begin{tabular}{|c|c|c|c|c|}
\hline \multicolumn{5}{|c|}{$\begin{array}{l}\text { Table 3.B Sensitivity Analysis: Variation in Technological Progress Rate } \\
\text { Percentage Change from Reference Case }\end{array}$} \\
\hline $1 \%, \%$ & \multicolumn{2}{|c|}{2000} & \multicolumn{2}{|c|}{2010} \\
\hline Output Variable & $\begin{array}{l}\text { Low } \\
\text { Case }\end{array}$ & $\begin{array}{l}\text { High } \\
\text { Case }\end{array}$ & $\begin{array}{l}\text { Low } \\
\text { Case }\end{array}$ & $\begin{array}{l}\text { High } \\
\text { Case }\end{array}$ \\
\hline Oil Production & $-1.8 \%$ & $2.5 \%$ & $-9.6 \%$ & $9.8 \%$ \\
\hline Oil Reserves & $-0.7 \%$ & $1.4 \%$ & $-7.7 \%$ & $8.8 \%$ \\
\hline Gas Production & $-1.9 \%$ & $2.0 \%$ & $-8.5 \%$ & $9.7 \%$ \\
\hline Gas Reserves & $-2.1 \%$ & $2.2 \%$ & $-8.1 \%$ & $9.2 \%$ \\
\hline Total Wells & $-4.4 \%$ & $4.6 \%$ & $-10.6 \%$ & $12.2 \%$ \\
\hline Oil Wells & $-3.5 \%$ & $3.7 \%$ & $-8.5 \%$ & $9.5 \%$ \\
\hline Gas Wells & $-5.4 \%$ & $5.8 \%$ & $-12.8 \%$ & $15.1 \%$ \\
\hline Dry Holes & $-4.0 \%$ & $4.2 \%$ & $-9.6 \%$ & $10.9 \%$ \\
\hline
\end{tabular}

The difference in the relative increase in oil and gas reserves reflects the relatively greater degree of depletion affecting oil compared to natural gas. Although the percentage changes in output variables vary between the technology tests; adjusting for the relative changes in the input variables reaffirms the symmetric nature of impact of the technology changes (Table 3.C). 


\begin{tabular}{|c|c|c|c|c|}
\hline - खो & & & & \\
\hline Output Variable & $\begin{array}{l}\text { Low } \\
\text { Case. }\end{array}$ & $\begin{array}{l}\text { High } \\
\text { Case }\end{array}$ & $\begin{array}{l}\text { Low } \\
\text { Case }\end{array}$ & $\begin{array}{l}\text { High } \\
\text { Case }\end{array}$ \\
\hline Oil Production & 0.04 & 0.05 & 0.19 & 0.20 \\
\hline Oil Reserves & 0.01 & 0.03 & 0.15 & 0.18 \\
\hline Gas Production & 0.04 & 0.04 & 0.17 & 0.19 \\
\hline Gas Reserves & 0.04 & 0.04 & 0.16 & 0.18 \\
\hline Total Wells & 0.09 & 0.09 & 0.21 & 0.24 \\
\hline Oil Wells & 0.07 & 0.07 & 0.17 & 0.19 \\
\hline Gas Wells & 0.11 & 0.12 & 0.26 & 0.30 \\
\hline Dry Holes & 0.08 & 0.08 & 0.19 & 0.22 \\
\hline
\end{tabular}

Drilling for all three types of well completions-oil, gas, and dry-shifts as expected. Drilling is higher given the assumptions of the High Technology test, and lower with Low Technology assumptions. The magnitude of the change in drilling levels is greatest for gas completions and least for oil. The relative impact of the test on dry holes has to fall between that for oil and gas due to the structure of the model: Dry holes are a consequence of oil or gas drilling, so the relative change in dry holes is a weighted average of the relative changes in oil and gas completions.

\section{Extraction Rate Tests}

The extraction rates altered for this test are those associated with new reserve additions. Aggregate production potential is affected incrementally with growth in the portion of total reserves that is composed of new reserve additions. The aggregate extraction rate asymptotically approaches the extraction rate for new reserve additions with the cumulative growth in new reserves during the projection periods.

The current structure of the OGSM estimates enhanced oil recovery (EOR) activity with an interpolation algorithm that derives production estimates from supply projections published by the National Petroleum Council (NPC). As such, OGSM does not employ an explicit extraction rate to determine EOR production. This feature of the model does not lend itself to extending this test to the EOR portion of the model. All test results include EOR at unchanged levels. 
The extraction rate tests provide a slight shift to the output variables (Table 4.A). Drilling does not change because prices and costs match Reference Case assumptions. The output variables of interest in these tests show a lesser shift than that observed in the first two tests.

\begin{tabular}{|c|c|c|c|c|c|c|c|}
\hline \multicolumn{8}{|c|}{$\begin{array}{l}\text { Table 4.A Sensitivity Analysis: Variation in Extraction Rates Case } \\
(-10 \% \text { or }+10 \%)\end{array}$} \\
\hline \multicolumn{2}{|c|}{$4 \% . \%, \%$} & \multicolumn{3}{|c|}{2000} & \multicolumn{3}{|c|}{$2010^{\circ}$} \\
\hline Output Variable & Units & $\begin{array}{l}\text { Low } \\
\text { Case }\end{array}$ & $\begin{array}{l}\text { Reference } \\
\text { Case }\end{array}$ & $\begin{array}{l}\text { High } \\
\text { Case }\end{array}$ & $\begin{array}{l}\text { Low } \\
\text { Case }\end{array}$ & $\begin{array}{l}\text { Reference } \\
\text { Case }\end{array}$ & $\begin{array}{l}\text { High } \\
\text { Caise }\end{array}$ \\
\hline Oil Production & $M B / D$ & 5,011 & 5,142 & 5,264 & 4,771 & 4,893 & 5,011 \\
\hline Oil Reserves̀ & $\mathrm{BB}$ & 19.10 & 18.86 & 18.63 & 17.86 & 17.14 & 16.91 \\
\hline Gas Production & TCFN & 14.28 & 14.83 & 15.33 & 14.76 & 15.21 & 15.59 \\
\hline Gas Reserves & TCF & 141.98 & 139.19 & 136.56 & 146.80 & 138.85 & 131.66 \\
\hline Total Wells. & Wells & 50,311 & 50,311 & 50,311 & 79,571 & 79,571 & 79,571 \\
\hline Oil Wells. & Wells & 18,076 & 18,076 & 18,076 & 26,906 & 26,906 & 26,906 \\
\hline Gas Wells & Welis & 19,858 & 19,858 & 19,858 & 33,436 & 33,436 & 33,436 \\
\hline Dry Holes & Wells & 12,377 & 12,377 & 12,377 & 19,228 & 19,228 & 19,228 \\
\hline
\end{tabular}

These tests show the production-and reserves estimates shifting in opposite directions (Table 4.B). For example, the increase in the extraction rate for new reserve additions raises the aggregate extraction rate in the High Extraction test, which leads to greater production initially. Production grows for a number of periods, but then growth relative to the Reference Case stops. The increased production without any other change to the cumulative quantity of reserve additions, results in a lower level of reserves. A greater quantity of cumulative production eventually causes reserves to be sufficiently less, so that the production is itself less than it otherwise would have been. Thus, as time.progresses, the greater drawdown from reserves mitigates the impact of the assumptions under the High Extraction test.

The ratio of percentage change in output relative to input (Table 4.C) corroborates this observation. The relative change in oil and gas production is. stable or slightly declining between 2000 and 2010. Oil and gas reserves, however, exhibit the cumulative impact of the greater drawdown from these reserves.

\section{Oil and Gas Prices}

Price variation affects the results of a standalone OGSM run by altering the drilling levels. Well completions add new reserve additions to the proved reserve stock and add to productive capacity 


\begin{tabular}{|c|c|c|c|c|}
\hline \multicolumn{5}{|c|}{$\begin{array}{c}\text { Table 4.B Sensitivity Analysis: Variation in Extraction Rates Case } \\
\text { Percentage Change from Reference Case }\end{array}$} \\
\hline अ ख & \multicolumn{2}{|c|}{2000} & \multicolumn{2}{|c|}{2010} \\
\hline Output Variable & $\begin{array}{l}\text { Low } \\
\text { Case }\end{array}$ & $\begin{array}{l}\text { High } \\
\text { Case }\end{array}$ & $\begin{array}{l}\text { Low } \\
\text { Case }\end{array}$ & $\begin{array}{l}\text { High } \\
\text { Case }\end{array}$ \\
\hline Oil Production & $0.0 \%$ & $2.4 \%$ & $0.0 \%$ & $2.4 \%$ \\
\hline Oil Reserves & $1.3 \%$ & $0.0 \%$ & $4.2 \%$ & $0.0 \%$ \\
\hline Gas Production & $0.0 \%$ & $3.4 \%$ & $0.0 \%$ & $2.5 \%$ \\
\hline Gas Reserves & $2.0 \%$ & $0.0 \%$ & $5.7 \%$ & $0.0 \%$ \\
\hline Total Wells & $0.0 \%$ & $0.0 \%$ & $0.0 \%$ & $0.0 \%$ \\
\hline Oil Wells & $0.0 \%$ & $0.0 \%$ & $0.0 \%$ & $0.0 \%$ \\
\hline Gas Wells & $0.0 \%$ & $0.0 \%$ & $0.0 \%$ & $0.0 \%$ \\
\hline Dry Holes & $0.0 \%$ & $0.0 \%$ & $0.0 \%$ & $0.0 \%$ \\
\hline
\end{tabular}

\begin{tabular}{|c|c|c|c|c|}
\hline \multicolumn{5}{|c|}{$\begin{array}{l}\text { Table 4.C Sensitivity Analysis: Variation in Extraction Rates Case } \\
\text { Ratio of Output to Input Percentage Changes }\end{array}$} \\
\hline bै। & \multicolumn{2}{|c|}{2000} & \multicolumn{2}{|c|}{2010} \\
\hline Output Variable & $\begin{array}{l}\text { Low } \\
\text { Case }\end{array}$ & $\begin{array}{l}\text { High } \\
\text { Case }\end{array}$ & $\begin{array}{l}\text { Low } \\
\text { Case }\end{array}$ & $\begin{array}{l}\text { High } \\
\text { Case }\end{array}$ \\
\hline Oil Production & 0.25 & 0.24 & 0.25 & 0.24 \\
\hline Oil Reserves & -0.13 & -0.12 & -0.42 & -0.13 \\
\hline Gas Production & 0.37 & 0.34 & 0.30 & 0.25 \\
\hline Gas Reserves & -0.20 & -0.19 & -0.57 & -0.52 \\
\hline Total Wells & 0.00 & 0.00 & 0.00 & 0.00 \\
\hline Oil Wells & 0.00 & 0.00 & 0.00 & 0.00 \\
\hline Gas Wells & 0.00 & 0.00 & 0.00 & 0.00 \\
\hline Dry Holes & 0.00 & 0.00 & 0.00 & 0.00 \\
\hline
\end{tabular}

by increasing the aggregate production-to-reserves ratio, which serves as the effective extraction rate.

There is no direct linkage between oil and NA gas activities on the supply side. AD gas occurs as a coproduct of oil; so changes in oil production alter total gas supply, but those results are not included in the present analysis for reasons previously discussed.

Price impacts are asymmetric in oil, but they are more balanced in natural gas (Tables 5.A and 5.B). The change in the input variables is itself not symmetric around the Reference Case values, but the pattern in the output results remains unchanged even when the percentage impact for 
production or reserves is adjusted for the relative change in the input variable (Table 5.C). This lack of symmetry may be related to the cumulative impact of price on drilling. The lesser change in gas prices leads to a corresponding change in gas drilling. The net impact on gas production, in effect, simply is lagging behind the impáct on oil. Thus, the larger sensitivity ratios for oil relative for gas would be misleading if they are interpreted as suggesting that oil production is clearly more sensitive than gas production to prices.

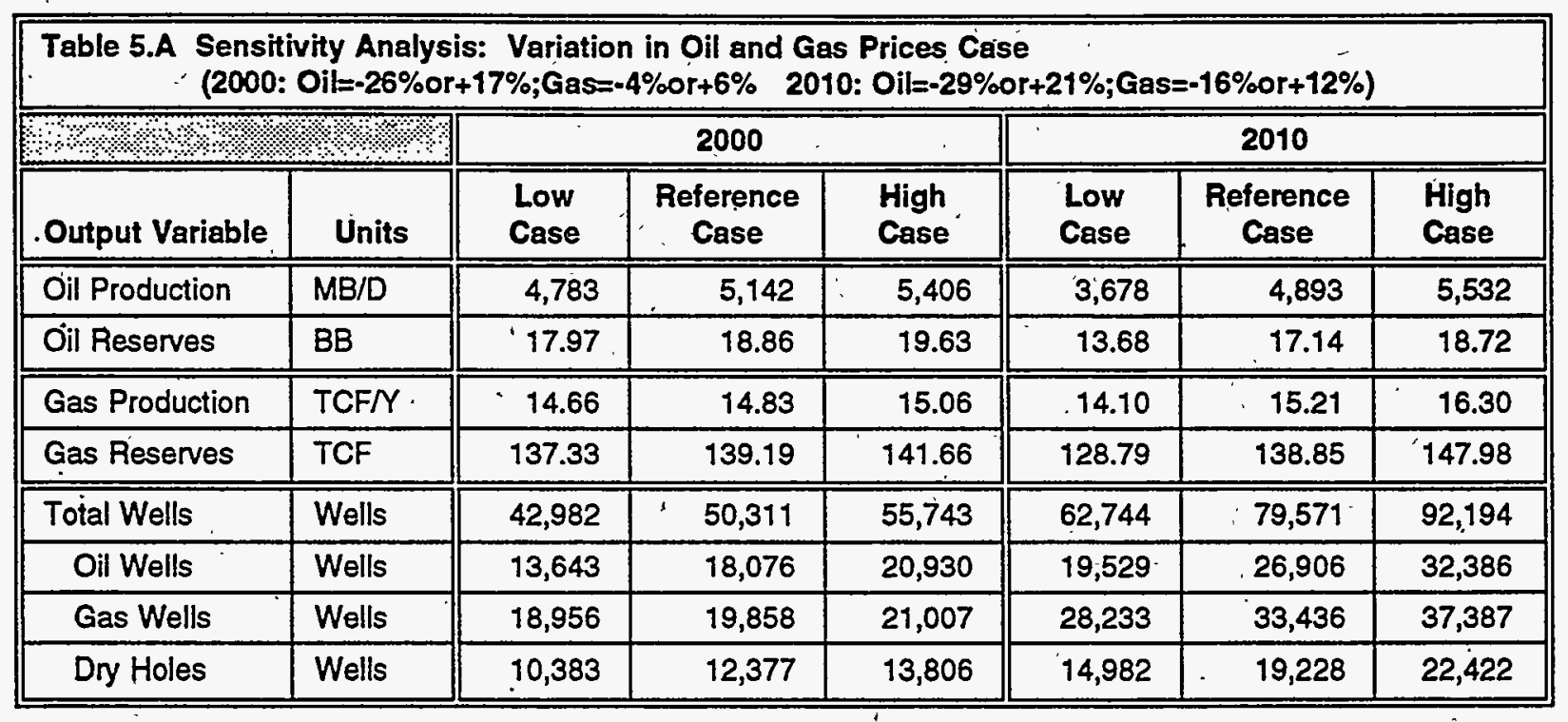

\begin{tabular}{|c|c|c|c|c|}
\hline \multicolumn{5}{|c|}{$\begin{array}{c}\text { Table 5.B Sensitivity Analysis: Variation in Oil and Gas Prices Case } \\
\text { Percentage Change from Reference Case }\end{array}$} \\
\hline$\because 42$ ४० & \multicolumn{2}{|c|}{2000} & \multicolumn{2}{|c|}{2010} \\
\hline Output Variable & $\begin{array}{l}\text { Low, } \\
\text { Case }\end{array}$ & $\begin{array}{l}\text { High } \\
\text { Case }\end{array}$ & $\begin{array}{l}\text { Low } \\
\text { Case }\end{array}$ & $\begin{array}{l}\text { High } \\
\text { Case }\end{array}$ \\
\hline Oil Production & $.7 .0 \%$ & $5.1 \%$ & $-24.8 \%$ & $13.1 \%$ \\
\hline Oil Reservès & $-4.7 \%$ & $4.1 \%$ & $-20.2 \%$ & $9.2 \%$ \\
\hline Gas Production & $-1.1 \%$ & $1.6 \%$ & $-7.3 \%$ & $7.2 \%$ \\
\hline Gas Reserves & $-1.3 \%$ & $.1 .8 \%$ & $-7,2 \%$ & $6.6 \%$ \\
\hline Total Wells & $-14.6 \%$ & $10.8 \%$ & $-21.1 \%$ & $15.9 \%$ \\
\hline Oil Wells. & $-24.5 \%$ & $15.8 \%$ & $-27.4 \%$ & $20.4 \%$ \\
\hline Gas Wells & $-4.5 \%$ & $5.8 \%$ & $-15.6 \%$ & $11.8 \%$ \\
\hline Dry Holes & $-16.1 \%$ & $.11 .5 \%$ & $-22.1 \%$ & $16.6 \%$ \\
\hline
\end{tabular}

The impact on production and reserves is not as pronounced as in the earlier test results. Those tests showed a significant change in production and reserves even though the drilling in two of the three cases did not change at all. In the current test, the impact of the change is realized first 


\begin{tabular}{|c|c|c|c|c|}
\hline \multicolumn{5}{|c|}{$\begin{array}{r}\text { Table 5.C Sensitivity Analysis: Variation in Oil and Gas Prices Case } \\
\text { Ratio of Fuel-Specific Output to Input Percentage Changes }\end{array}$} \\
\hline ओ आ। & \multicolumn{2}{|c|}{2000} & \multicolumn{2}{|c|}{2010} \\
\hline Output Variable & $\begin{array}{l}\text { Low } \\
\text { Case }\end{array}$ & $\begin{array}{l}\text { High } \\
\text { Case }\end{array}$ & Low & $\begin{array}{l}\text { High } \\
\text { Case }\end{array}$ \\
\hline Oil Production & 0.28 & 0.31 & 0.87 & 0.62 \\
\hline Oil Reserves & 0.19 & 0.24 & 0.71 & 0.44 \\
\hline Gas Production & 0.26 & 0.27 & 0.46 & 0.61 \\
\hline Gas Reserves & 0.30 & 0.31 & 0.46 & 0.56 \\
\hline Total Wells & $N^{*} A^{*}$. & $N A^{*}$ & $N / A^{*}$ & $N A^{*}$ \\
\hline Oil Wells & 0.97 & 0.95 & 0.96 & 0.97 \\
\hline Gas Wells & 1.03 & 1.00 & 0.98 & 1.01 \\
\hline Dry Holes & $N / A^{*}$ & $N / A^{*}$ & $N / A^{*}$ & N/A \\
\hline
\end{tabular}

N/A": The 'Total Wells' and 'Dry Holes' categories are excluded from fuel-specific computations because these categories combine oil and gas activities.

in the drilling levels. Productivity is affected in any year only as the cumulative drilling level varies.

\section{5: Drilling Costs}

A change in drilling costs alters the number of well completions in direct proportion to the magnitude of the cost shift. The current structure of the OGSM does not lend itself to include Alaska or EOR in this test of OGSM sensitivity to drilling costs. - The Alaska submodule uses drilling costs to evaluate the economic potential for an allowable drilling program. The economic evaluation serves only as a rudimentary filtering process. The methodology of the Alaska submodule allows an expected number of new exploratory wells each year. It does not permit unconstrained drilling of all economically viable projects. This limitation mirrors industry operations in Alaska, which are affected by operational, institutionial, and weather as limiting factors. The EOR submodule derives production estimates from supply projections published by the NPC as described earlier in this report. This feature of the model does not lend itself to extending this test to the EOR portion of the model. All test results include Alaska and EOR variable values at unchanged levels.

The impact of drilling costs is uniform across the well types. Given that the well counts are proportional to drilling costs, a 20 percent decline in cost causes an increase of 25 percent in well completions, other things being equal, while a 20 percent increase lowers drilling 16.7 percent (Tables 6.A and 6.B). The sign of the change for each table cell is the opposite of most of the 
preceding test results because an increase in drilling costs reduces drilling, while a decrease stimulates drilling.

\begin{tabular}{|c|c|c|c|c|c|c|c|}
\hline \multicolumn{5}{|c|}{$\begin{array}{l}\text { Table 6.A Sensitivity Analysis: 'Variation in Drilling Costs Casé } \\
(-20 \% \text { or }+20 \%)\end{array}$} & \multicolumn{3}{|l|}{ 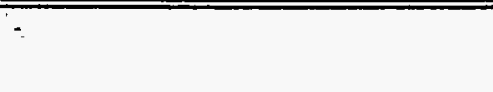 } \\
\hline \multicolumn{2}{|c|}{ 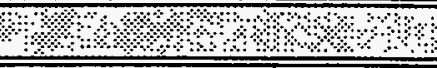 } & \multicolumn{3}{|c|}{2000} & \multicolumn{3}{|c|}{2010} \\
\hline Output Variable & Units & $\begin{array}{l}\text { Low } \\
\text { Case }\end{array}$ & $\begin{array}{l}\text { Reference } \\
\text { Case }\end{array}$ & $\begin{array}{l}\text { High } \\
\text { Case }\end{array}$ & $\begin{array}{l}\text { Low } \\
\text { Case }\end{array}$ & $\begin{array}{l}\text { Reference } \\
\text { Case }\end{array}$ & $\begin{array}{l}\text { High } \\
\text { Case }\end{array}$ \\
\hline Oil Production & $M B / D$ & 5,446 & 5,142 & 4,915 & 5,238 & 4,893 & 4,616 \\
\hline Oil Reserves & BB & 19.76 & 18.86 & 18.18 & 1.8 .08 & 17.14 & 16.39 \\
\hline Gas Production & TCF $/ Y$ & 16.12 & 14.83 & . 13.85 & 16.73 & 15.21 & .14 .09 \\
\hline Gas Reserves & TCF & $15,0.95$ & 139.19 & 130.33 & 151.48 & 138.85 & 129.33 \\
\hline Total Wells & Wells & 62,889 & $\overline{50,311}$ & 41,926 & 99,463 & 79,571 & 66,309 \\
\hline Oll Wells & Wells" & 22,596 & 18,076 & 15,064 & 33,632 & 26,906 & 22,421 \\
\hline Gas Wells & Wells' & 24,823 & 19,858 & 16,549 & 41,796 & 33,436 & 27,864 \\
\hline Dry Holes & Wells & 15,471 & 12,377 & 10,314 & $.24,036$ & 19,228 & 16,024 \\
\hline
\end{tabular}

\begin{tabular}{|c|c|c|c|c|}
\hline \multicolumn{5}{|c|}{$\begin{array}{c}\text { Table 6.B Sensitivity Analysis: Variation in Drilling Costs Case } \\
\text { ‘ Percentage Change from Reference Case }\end{array}$} \\
\hline ४ै। & \multicolumn{2}{|c|}{2000} & \multicolumn{2}{|c|}{2010} \\
\hline Output Variable & $\begin{array}{l}\text { Low } \\
\text { Case }\end{array}$ & $\begin{array}{l}\text { High } \\
\text { Case }\end{array}$ & $\begin{array}{l}\text { Low } \\
\text { Case }\end{array}$ & $\begin{array}{l}\text { High } \\
\text { Case }\end{array}$ \\
\hline Oil Production & $5.9 \%$ & $-4.4 \%$ & $7.1 \%$ & $-5.7 \%$ \\
\hline Oil Reserves & $4.8 \%$ & $-3.6 \%$ & $5.5 \%$ & $-4.4 \%$ \\
\hline Gas Production & $8.7 \%$ & $-6.6 \%$ & $10.0 \%$ & $-7.4 \%$ \\
\hline Gas Reserves & $8.4 \%$ & $-6.4 \%$ & $9: 1 \%$ & $-6.9 \%$ \\
\hline Total Wells & $25.0 \%$ & $-16.7 \%$ & $25.0 \%$ & $-16.7 \%$ \\
\hline Oil Wells & $25.0 \%$ & $-16.7 \%$ & $25.0 \%$ & $-16.7 \%$ \\
\hline Gas Wells & $25.0 \%$ & $-16.7 \%$ & $25.0 \%$ & $-16.7 \%$ \\
\hline Dry Holes & $25.0 \%$ & $-16.7 \%$ & $25.0 \%$ & $-16.7 \%$ \\
\hline
\end{tabular}

The impact on production is greater than the effect on reserves: . This stems from the effect of drilling on extraction rates as well as on reserves. The extraction rates on new reserve additions are greater than the initial aggregate average rate, thus raising the weighted average extraction rate. For example, in the Low Drilling Cost test, the increased drilling raises the reserve stock in each period and also the relative production potential for that stock. Thus, the reserves are higher than in the Reference Case, and production is greater still, although the effect is not great. 


\begin{tabular}{|c|c|c|c|c|}
\hline आण आ & & & & \\
\hline Output Variable & $\begin{array}{l}\text { Low } \\
\text { Case }\end{array}$ & $\begin{array}{l}\text { High } \\
\text { Case }\end{array}$ & $\begin{array}{l}\text { Low } \\
\text { Ceise }\end{array}$ & $\begin{array}{l}\text { High } \\
\text { Case }\end{array}$ \\
\hline Oil Production & -0.30 & -0.22 & -0.35 & -0.28 \\
\hline Oil Reserves & -0.24 & -0.18 & -0.27 & -0.22 \\
\hline Gas Production & -0.43 & -0.33 & -0.50 & -0.37 \\
\hline Gas Reserves & -0.42 & -0.32 & -0.45 & -0.34 \\
\hline Total Wells & -1.25 & -0.83 & -1.25 & -0.83 \\
\hline Oil Wells & -1.25 & -0.83 & -1.25 & -0.83 \\
\hline Gas Wells & -1.25 & -0.83 & -1.25 & -0.83 \\
\hline Dry Holes & -1.25 & -0.83 & -1.25 & -0.83 \\
\hline
\end{tabular}

\section{Drilling Response Parameters}

This test analyzes the impact of changes to the drilling function, by altering the value of the price response term in the function. The absence of an explicit drilling component for the EOR representation does not allow the inclusion of this submodule in this model test. All results reflect EOR activities at the Reference Case levels.

As in the previous two tests, the impact is realized through changes in well completions, which in turn varies the reserve stock and the aggregate extraction rate. The impact builds cumulatively (Table 7.A). The relative change is similar for both fuels between the Low and High Drilling Response tests (Table 7.B and 7.C).

\section{Comparison of Results Across'Tests}

The presentation in this section addresses the differences between each output variable across the set of six tests. This comparison of variation in each output variable focuses on the differential impact of the tests. The discussion in this section relies on the five figures (2 through 6 ) and the ratios in the " $\mathrm{C}$ " tables. The figures serve as the basis for a convenient visual inspection of the variation.in results between test cases. The ratios in the " $C$ " tables show the degree of model sensitivity measured as a change in the output variable relative to the change in the input variable. 


\begin{tabular}{|c|c|c|c|c|c|c|c|}
\hline \multicolumn{8}{|c|}{$\begin{array}{l}\text { Table 7.A Sensitivity Analysis: Variation in Drilling Response Case } \\
(-10 \% \text { or }+10 \%)\end{array}$} \\
\hline \multicolumn{2}{|c|}{ ४ै। } & \multicolumn{3}{|c|}{2000} & \multicolumn{3}{|c|}{2010} \\
\hline Outpu't Variable & Units. & $\begin{array}{l}\text { Low } \\
\text { Case }\end{array}$ & $\begin{array}{l}\text { Reference } \\
\text { Case }\end{array}$ & $\begin{array}{l}\text { High } \\
\text { Case }\end{array}$ & $\begin{array}{l}\text { Low } \\
\text { Case }\end{array}$ & $\begin{array}{l}\text { Reference } \\
\text { Case }\end{array}$ & $\begin{array}{l}\text { High } \\
\text { Case }\end{array}$ \\
\hline Oil Production. & $M B / D$ & 5,065 & 5,142 & 5,212 & 4,719 & 4,893 & 5,058 \\
\hline Oil Reserves & $\mathrm{BB}$ & 18.55 & 18.86 & 19.14 & 16.59 & 17.14 & 17.67 \\
\hline Gas Production & TCEN. & .14 .46 & 14.83 & 15.17 & 14.55 & 15.21 & 15.85 \\
\hline Gas Reserves & TCF & 135.42 & 139.19 & 142.69 & 132.68 & 138.85 & 144.83 \\
\hline Total Wells & Wells & 45,637 & 50,311 & 54,953 & 69,859 & 79,571 & 89,810 \\
\hline Oil Wells & Wells & 16,369 & 18,076 & 19,771 & 23,668 & 26,906 & 30,297 \\
\hline Gas Wells & Wells & 17,977 & 19,858 & 21,736 & 29,186 & 33,436 & 37,958 \\
\hline Dry Holes & Wells & 11,291 & 12,377 & 13,446 & 17,005 & 19,228 & 21,554 \\
\hline
\end{tabular}

\begin{tabular}{|c|c|c|c|c|}
\hline \multicolumn{5}{|c|}{$\begin{array}{l}\text { Table 7.B Sensitivity Analysis: Variation in Drilling Response Case } \\
\text { Percentage Chánge from Reference Case }\end{array}$} \\
\hline ४ै४४४४४ & \multicolumn{2}{|c|}{2000} & \multicolumn{2}{|c|}{2010} \\
\hline Output Variable & $\begin{array}{l}\text { Low } \\
\text { Case }\end{array}$ & $\begin{array}{l}\text { High } \\
\text { Case }\end{array}$ & Low & $\begin{array}{l}\text { High } \\
\text { Case }\end{array}$ \\
\hline Oil Production & $-1.5 \%$ & $1.4 \%$ & $-3.6 \%$ & $3.4 \%$ \\
\hline Oil Reserves & $-1.6 \%$ & $1.5 \%$ & $-3.2 \%$ & $3.1 \%$ \\
\hline Gas Production & $-2.5 \%$ & $2.3 \%$ & $-4.3 \%$ & $4.2 \%$ \\
\hline Gas Reserves. & $-2.7 \%$ & $2.5 \%$ & $-4.4 \%$ & $4.3 \%$ \\
\hline Total Wells & $-9.3 \%$ & $9.2 \%$ & $-12.2 \%$ & $12.9 \%$ \\
\hline Oil Wells & $-9.4 \%$ & $9.4 \%$ & $-12.0 \%$ & $12.6 \%$ \\
\hline Gas Weills & $-9.5 \%$ & $9.5 \%$ & $-12.7 \%$ & $13.5 \%$ \\
\hline Dry Holes & $-8.8 \%$ & $8.6 \%$ & $-11.6 \%$ & $12.1 \%$ \\
\hline
\end{tabular}

Each figure consists of two graphs that exhibit the percentage differences for each period between the test results and the Reference Case for each of the five output variables: oil production (Figure 2), NA gas production (Figure 3), oil reserves (Figure 4), NA gas reserves (Figure 5), and total wells (Figure 6). The two graphs in each set present the results from three tests. The first set of results is the group in which the input variable affects the productivity of supply activities in the model: economically recoverable resource estimates, technology progress factors, and extraction rates. Changes to the resource estimates and technology factors alter the resource productivity of exploratory and developmental drilling. Technology also impacts the cost of - drilling, and thus, the number of well completions. The extraction rate parameters represent the expected production potential of the new proved reserve additions. The last three variables (oil 


\begin{tabular}{|c|c|c|c|c|}
\hline \multicolumn{5}{|c|}{$\begin{array}{c}\text { Table 7.C Sensitivity Analysis: Variation in Drilling Response Case } \\
\text { Ratio of Output to Input Percentage Changes }\end{array}$} \\
\hline ओ ४। & \multicolumn{2}{|c|}{2000} & \multicolumn{2}{|c|}{2010} \\
\hline Output Variable & $\begin{array}{l}\text { Low } \\
\text { Case }\end{array}$ & $\begin{array}{l}\text { High } \\
\text { Case }\end{array}$ & $\begin{array}{l}\text { Low } \\
\text { Case }\end{array}$ & $\begin{array}{l}\text { High } \\
\text { Case }\end{array}$ \\
\hline Oil Production & 0.15 & 0.14 & 0.36 & 0.34 \\
\hline Oil Reserves & 0.16 & 0.15 & 0.32 & 0.31 \\
\hline Gas Production & 0.25 & 0.23 & 0.43 & 0.42 \\
\hline Gas Reserves . & 0.27 & 0.25 & 0.44 & 0.43 \\
\hline Total Wells & 0.93 & 0.92 & 1.22 & 1.29 \\
\hline Oil Wells & 0.94 & 0.94 & 1.20 & 1.26 \\
\hline Gas Wells & 0.95 & 0.95 & 1.27 & 1.35 \\
\hline Dry Holes & 0.88 & 0.86 & 1.16 & 1.21 \\
\hline
\end{tabular}

and gas wellhead prices, drilling costs, and drilling response parameters), along with technology, affect the level of drilling, which in turn alters the reserve stock and production potential in any projection year. This grouping has logical appeal and it also avoids obscuring the results, which is likely if test results for all input variables were crowded into a single graph.

\section{Oil and Gas Production}

The percentage variation in production estimates generally were stronger in the case of oil (Figure 2) compared to natural gas (Figure 3). Results in the economically recoverable resource test show the greatest deviation from the Reference Case. The extraction rate test shows a strong impact in the early years of the projection. This stems from the direct linkage between the input variable in this test and estimated production. The distinct early shift is arrested within a few years, followed by a steady trend relative to the Reference Case. The lack of continual change in the level of production is related to the contrary affect on reserves, which serves as a mitigating factor in the test analysis. In the high extraction rate test, for example, the higher rate of extraction does increase production from a given level of reserves. However, the greater drawdown rate reduces the level of reserves, offsetting the gains of the enhanced extraction rate.

The shift in drilling costs produces more change in gas production than oil-production. This is related to the larger number of gas wells than oil wells in the outlook. The shift in well completions due to the change in costs reflects a larger number of gas completions compared to: oil completions. 
Figure 2. Variation in Oil Production by Scenario
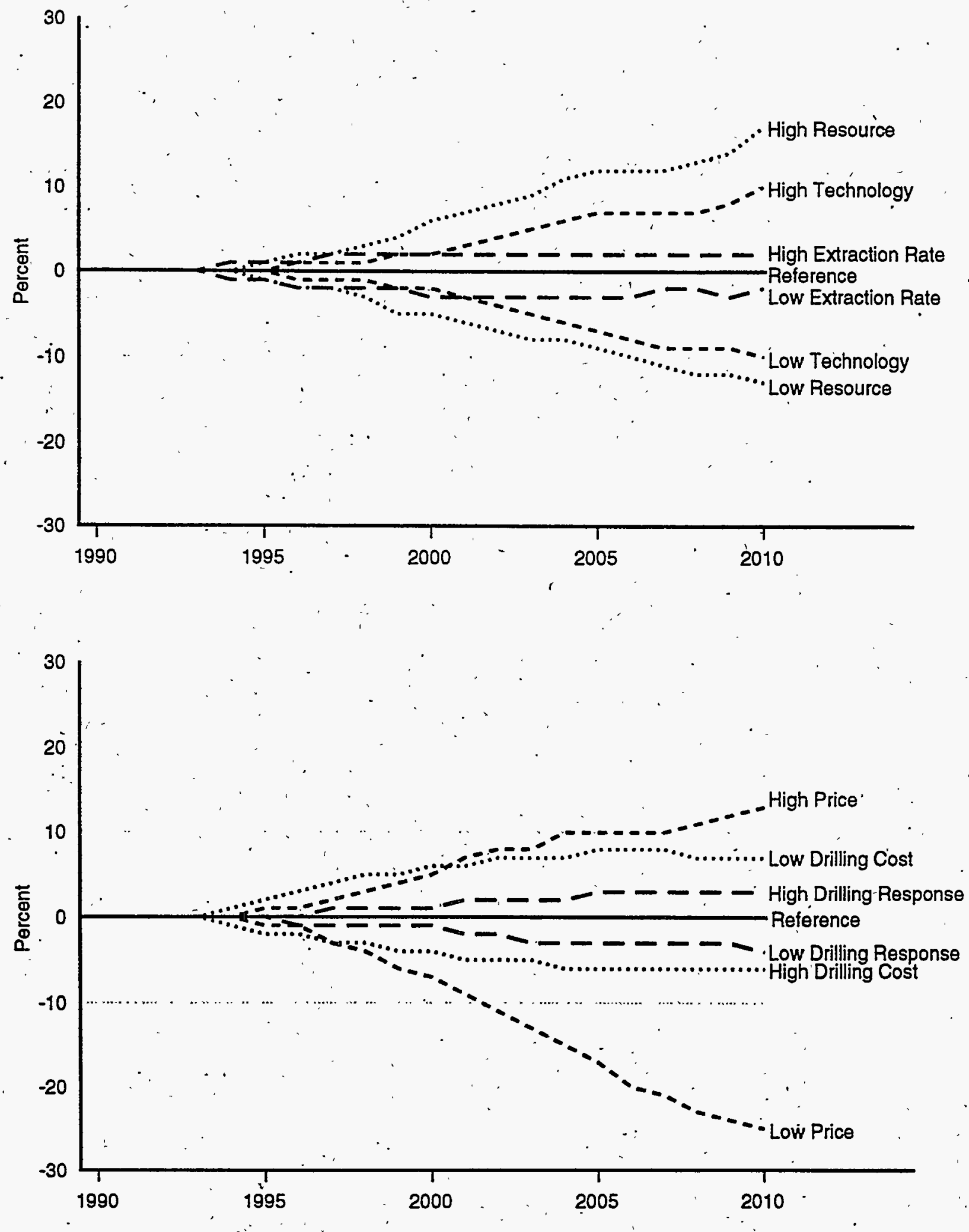

Documentation of the Oil and Gas Supply Module (OGSM) 
Figure 3. Variation in Nonassociated Gas Production by Scenario
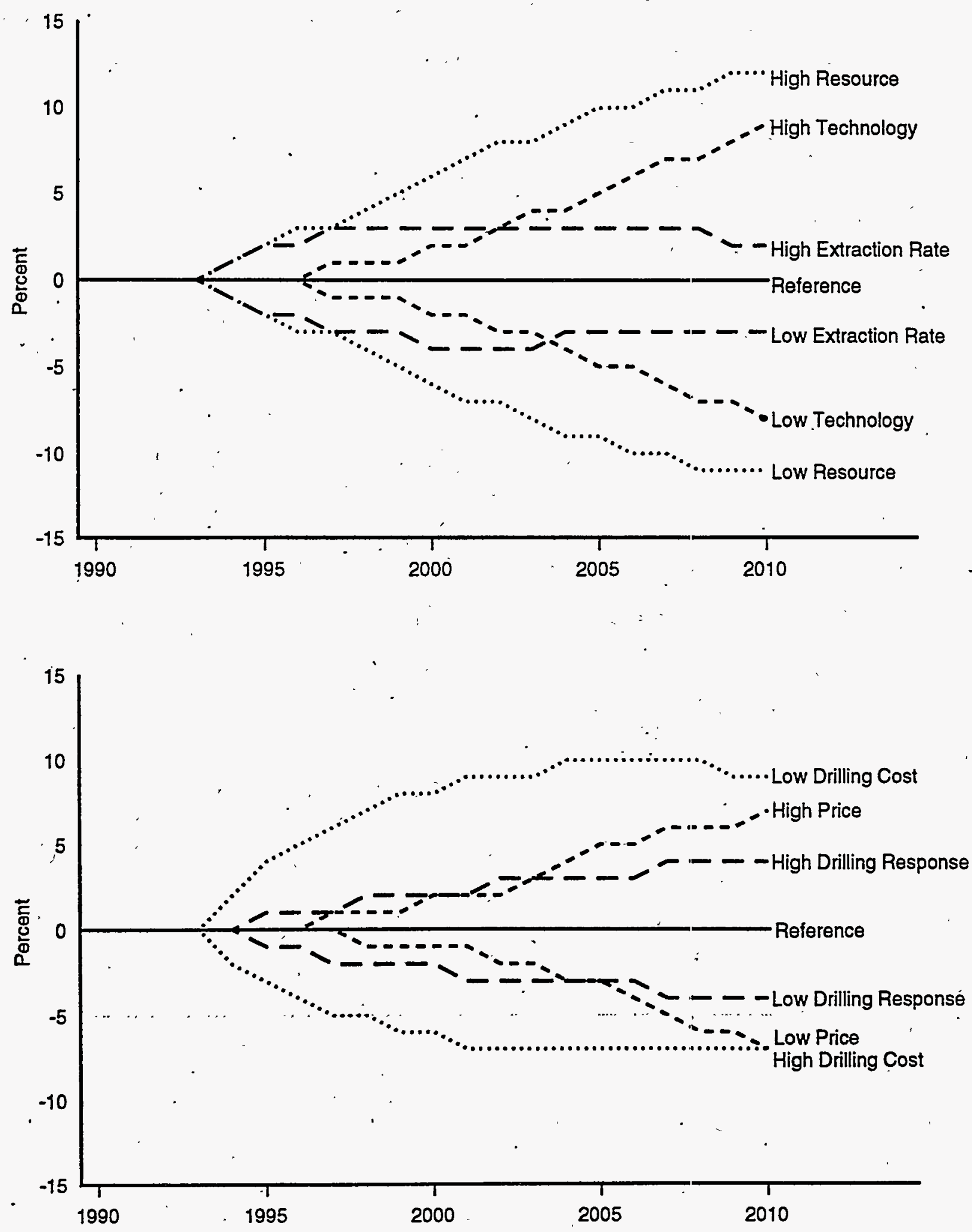
Figure 4. Variation in Oil Reserves by Scenario
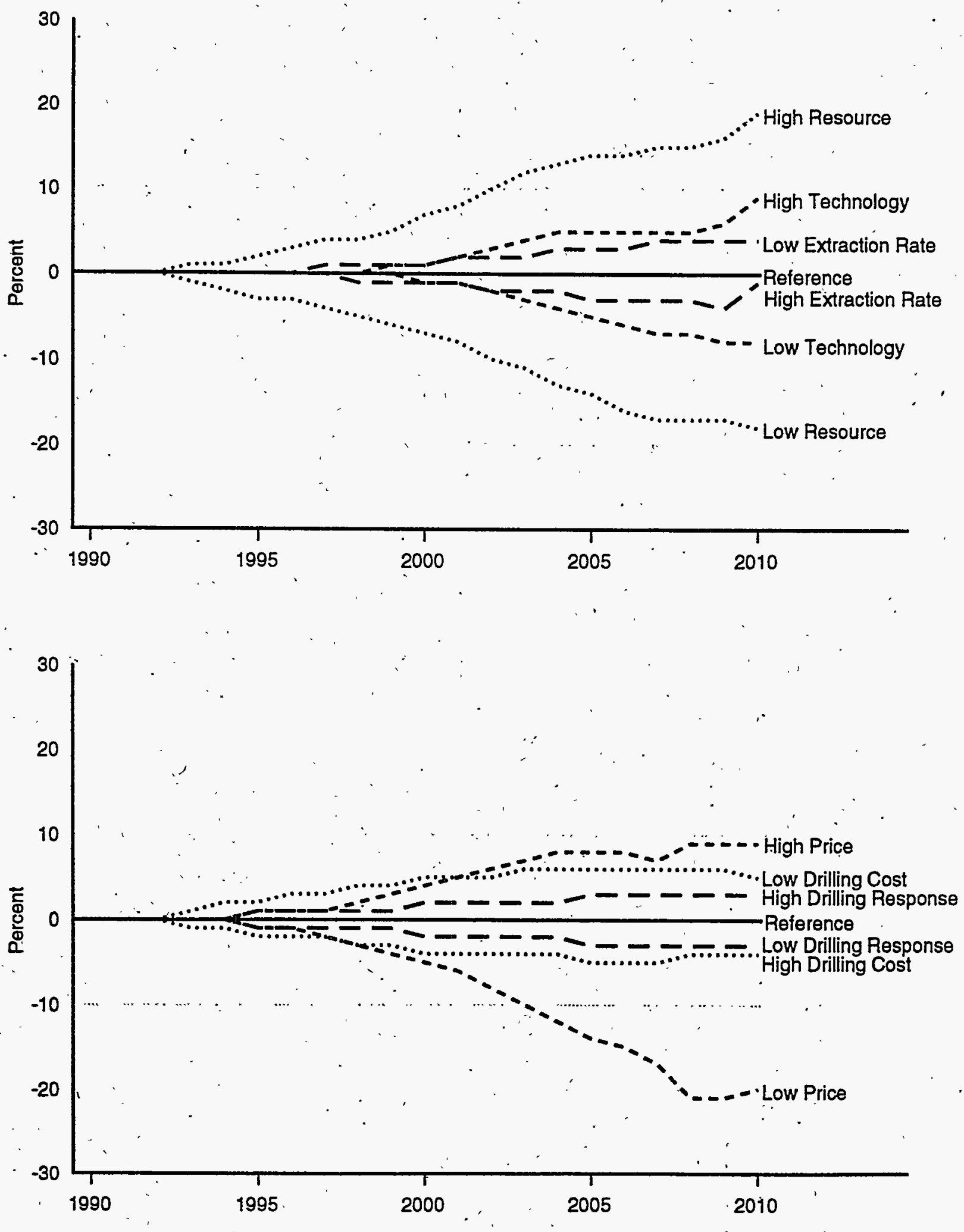

Documentation of the Oll and Gas Supply Module (OGSM) 
Figure 5. Variation in Gas Reserves by Scenario
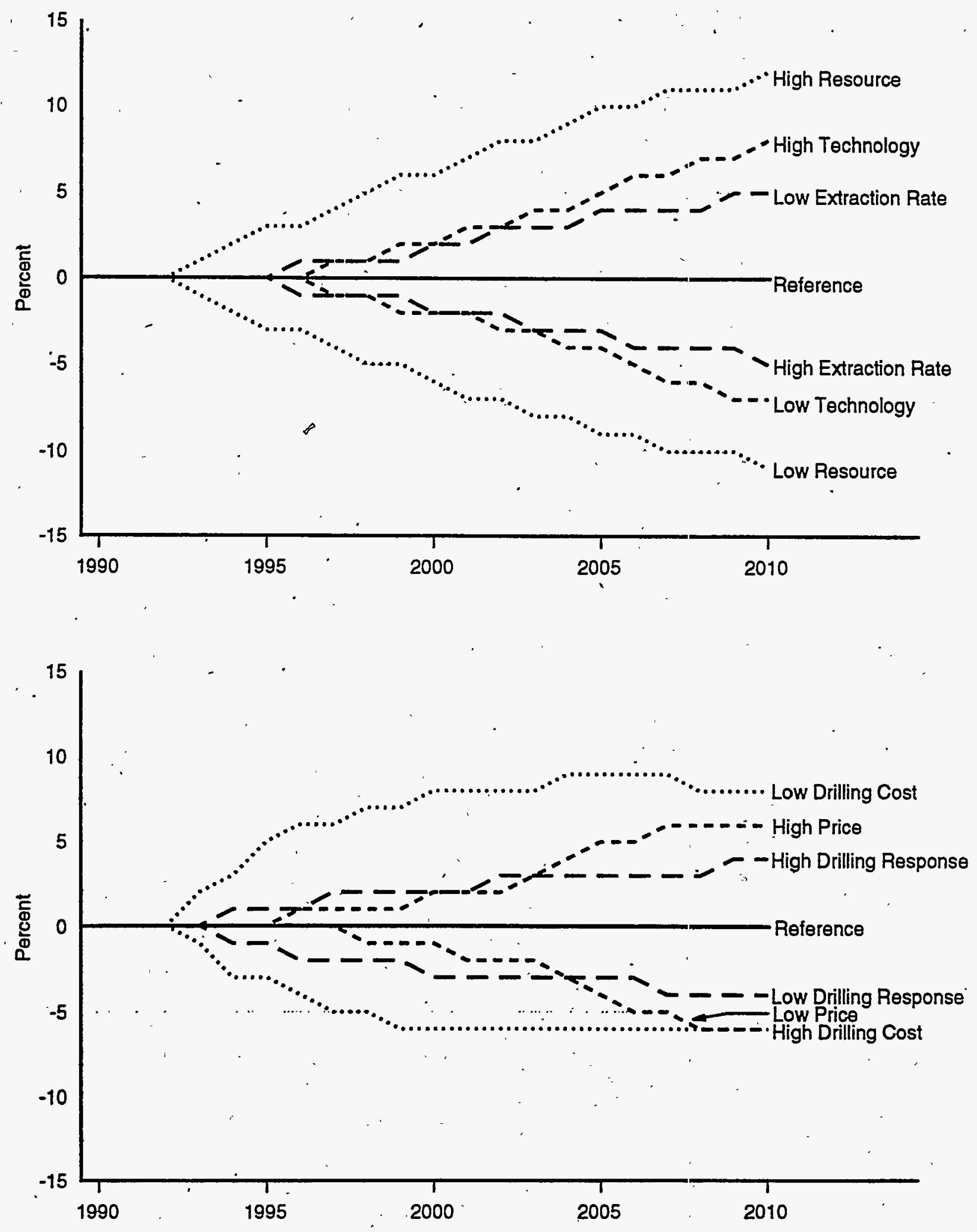

Documentation of the Oil and Gas.Supply Module (OGSM) 
Figure 6. Variation in. Wells Drilled by Scenario
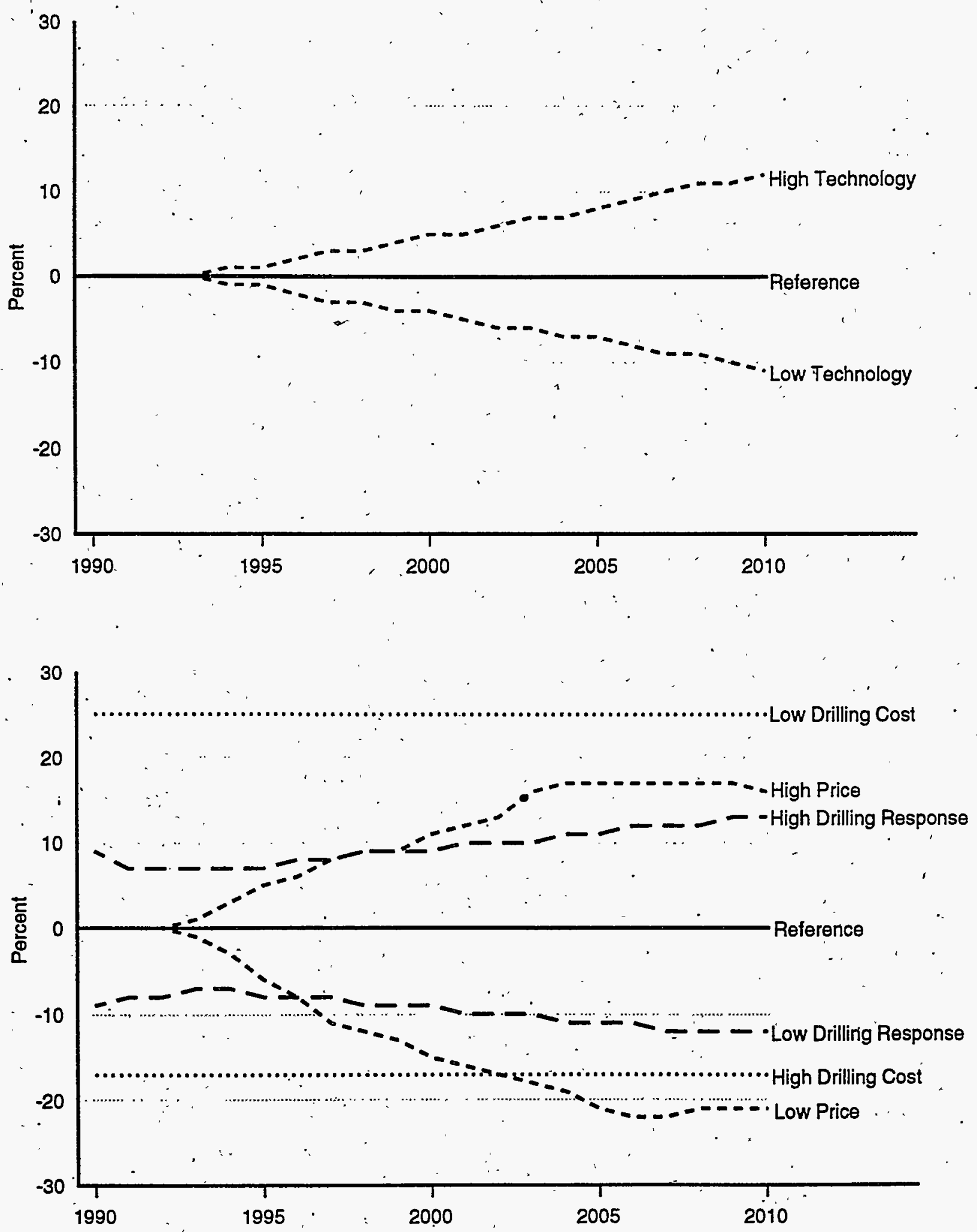

Note: Drilling activity did not vary from the reference case in the recovery and extraction rate cases. 
The sensitivity-ratios (Tables 2.C to 7.C) indicate that at least some share of the output variation is related to the magnitude of the change in the input variables. The most influential variable for the outlook is the wellhead price. The sensitivity ratios for 2010 oil production are 0.62 and 0.87 for the Low and High Recovery tests, respectively. Gas production shows changes of a similar magnitude, 0.61 and 0.46 for the Low and High Recovery tests. Oil production is more sensitive to the resource estimates than is the case for gas, roughly 0.5 for oil in both tests and 0.26 and 0.42 for gas.

The selected output variables generally show the least sensitivity to the assumed rate of technological change as measured by the sensitivity ratios. However, this feature of the analysis should not be interpreted as leading directly to the conclusion that technology will have a limited impact in the future. Such a perception of the results is misleading in the sense that each factor that affects the outlook has a probability of occurrence. The assessinent of the potential for any input variable to materially alter the outlook must combine the sensitivity of the outlook to changes in the factor, and the likelihood of large deviations from the Reference Case values. For example, if high rates of technological progress have high probabilities of occurrence, it should be viewed as a factor with considerable potential to vary the outlook even though the outlook is not as sensitive to it as other factors.

\section{Oil and Gas Reserves}

There are a number of similarities to the characteristics in production that arise in the comparison of oil and gas reserves across the test cases. Percentage variation in reserves estimates generally were stronger for oil (Figure 4) than natural gas (Figure 5). Results in the economically recoverable resource tests show the greatest deviation from the Reference Case, except for low oil production. Low oil prices drove down oil production more st:ongly than the effect of the low oil resource estimate.

The extraction rate test does not show as strong an impact on reserves in the early years of the projection as was the case with production. The sizeable impact of the change on production in this test represents only a small fraction of the much larger reserve stock for each fuel. The effect on reserves does grow cumulatively, however, in contrast to production, which reaches a relatively stable plateau. This change to the stock variable, reserves, reflects the difference in net flows of production and reserve additions in this test.

Most changes to input variables that increase production have shifts in reserve levels in the same direction, although not necessarily of equal magnitude. The exception is extraction rates, which 
are discussed later in this. section. This aspect of the results suggests that the benefits or costs associated with variatio: in the initial inputs are shared between production and reserves. This is a significant observation in that more or less reserves often are viewed as an indication of more or less security of supply. A change in industry circumstances leading to a higher extraction rate has th: offsetting feature that supplies in the following years are not as secure as before. In fact, a surge in natural gas supply in the short-term may lower prices thereby jeopardizing exp:cted supplies further.

The extraction rate should not be confused with the recovery factor. The recovery factor is a measure of the fraction of original resources-in-place that is recovered through production. Although increased recovery may have a negative impact on prices over time, other things being equal, it enhances the reserve stock by. increasing the volume of proved reserves in the set of discovered fields. Thus, increased recovery factors avoid the net drawdown of reserves directly attributable to higher extraction rates. Recovery factor variation is not an analysis option in the current version of OGSM. The economically recoverable resource estimates reflect an assumed recovery level, but the lack of an explicit recovery parameter does not lend itself to proper sensitivity ànalysis.

The shift in drilling costs produces more change in gas reserves than oil reserves. As is the case with production, this is related to the larger number of gas wells than oil wells in the outlook. The shift in the larger number of gas well completions due to the change in costs affects the rate of reserve replacement more strongly, thus varying the reserve stock.

The sensitivity ratios (Tables 2.C to 7.C) indicate that the degree of the reserves variation relates to the magnitude of the change in the input variables. This feature of the results is similar to the pattern of change in production. Once again, a key influential variable for the outlook is the wellhead price, with ratios ranging from 8.44 to 0.71 for 2010 oil reserves, and 0.46 to 0.56 for natural gas reserves. The Low and High Recovery tests show sensitivity ratios ranging from 0.26 to $\mathbf{2 . 7 5}$, indicating a stronger impact on reserves compared to production. Given the relationship between reserves and production, the larger change in reserves suggest that production can be expected to increase further at least in the years immediately beyond 2010 .

The technology rate generally has the least impact on reserves of all input variables, when adjusted for the magnitude of the input change. This result is comparable to the pattern of change in the production levels. As discussed earlier, this feature of the analysis should not be interpreted as meaning that technology will have a limited impact in the future. The potential 
for technology to alter the outlook depends greatly on the likelihood that the realized rate in the future will deviate markedly from the Reference Case values.

\section{Drilling}

Total well completions vary greatly in response to changes in the input variables ${ }^{7}$.Figure 6). The strongest response occurred with a change in drilling costs, which causes a direct shift in well completions. The modification in wells translates into changes in reserves and production. The direction of the production and reserves changes matches the shift in drilling, but it is not necessarily of equal magnitude.

The price tests show that the industry responds strongly to a change in economic incentives. The trend in prices does not incite an early pronounced shift in drilling, as occurs in the drilling cost test, but the impact is more gradual. The change in the drilling response factor similarly has a gradual effect. The impact is not as great as in the drilling cost or price tests, but it is comparable to the shift in well completions due to a change in technology rates. The impact of technology on production and reserves is greater than the change in drilling response because of its effect on drilling productivity.

\section{Findings}

The Model Developers Report (MDR) analysis provides a number of significant insights into the performance of the OGSM. The results generally conform to expectations regarding the direction and relative magnitude of the expected changes. The results, however, are conditional on both the specific manner in which the test was conducted and the methodology of OGSM itself. Certain aspects of the analysis provide an appreciation for the performance characteristics of the model, and others indicate elements of the model in which methodological enhancements might yield an improved representation of basic relations within the industry.

Findings of the analysis include:

- Drilling is unchanged in the economically recoverable resource and extraction rate tests because drilling in the $A E O 94$ version of OGSM is a function of prices, costs, and the drilling equation parameters alone. 
- The responsiveness of production, reserves, and drilling to changes in input variables is generally inelastic; that is, the ratio of the percentage change in the output variable to the percentage change in the input variable is less than 1.0.

- Most changes in inputs result in production, reserve, and drilling shifts in the same direction.

- The benefits or costs associated with variation in the initial inputs are shared between production and reserves. The impact of changes in economic conditions, technology rates, or policy actions can be understated if changes beyond production effects are ignored.

- Changes in production and reserves due to variation in any input variable are generally cumulative. The impacts are realized as the reserve stock and productive extraction rate are modified incrementally:

- Improved extraction rates accelerate the rate of recovery from any stock of reserves, but continued higher production depends on the rate of net reserves replacement. Increased extraction rates do not necessarily lead to ever greater increases in production, absent a higher rate of reserve additions.

- Geology is more significant than technology. (This conclusion is tentative owing to the conceptual difficulty in comparing variation in, and the impact due to, technology and the resource base.)

The OGSM outputs remain within a reasonable range, with respect to changes to the most important inputs and so they may be considered not ill-conditioned. The OGSM is generally well-behaved -in that the magnitude and direction of changes in results are reasonable. Consequently, the OGSM does not appear to contribute to instability in the rest of the NEMS system. Models never attain a state of being final, however, and OGSM would be enhanced with a number of methodological changes, including the following.

- Drilling should be a function of expected profitability as described in the earlier Component Design Reports. This would allow the model to incorporate the prices, costs, and productivity as economic influences on drilling decisions. 
- In the future, depletion of the resource base is expected to reduce the finding rate, which will reduce the expected returns from drilling. An explicit linkage between the finding rate and expected returns from drilling would allow the model to better represent effects of resource depletion on supply activities. This aspect of the model will be investigated as an enhancement to be incorporated into the model during. 1995. The impact of this difference cannot be determined without further study, although it is not expected to be decisive in the model results.

- Technology should be incorporated into the methodology on a more detailed level. This would allow the user-analyst to specify the impact of technological change by region, resource category, supply activity (for example, drilling, operating, lease equipment), and . other relevant factors (for example, success rates). This review of the implementation of technology and its design and implementation in OGSM is being conducted as a special . analysis task. The task is scheduled for completion by the end of calendar year 1994. 


\section{Appendix A. References}

Fisher, W.L., et al, 1988, An Assessment of the Natural Gas Resource Base of the United States, Bureau of Economic Geology, University of Texas at Austin, Austin, Texas.'

National Petroleum Council. 1984. Enhanced Oil Recovery, Washington, D.C.

National Petroleum Council. 1992. The Potential for Natural Gas in the United States, Washington, DC.

Potential Gas Committee. 1992a. Potential Supply of Natural Gas in the United States, Potential Gas Agency, Colorado School of Mines, Golden, Colorado.

U.S. Department of Energy. 1989. An Examination of Domestic Natural Gas Resource Estimates, SR/RNGD/89-01, Energy Information Administration, Washington, DC.

U.S. Department of Energy. 1990. The Domestic Oil and Gas Recoverable Resource Base: Supporting Analysis for the National Energy. Strategy, SR/NES/90-05, Energy Information Administration, Washington, DC.

United States Department of Energy. March 1994. Documentation for the Oil and Gas Supply Module (OGSM), Energy Information Administration, DOE/EIA-M063.

United States Department of Energy. 1993a. Annual Energy Outlook 1993, Energy Information Administration, DOE/EIA-0554(93).

United States Department of Energy. 1993a. U.S. Crude Oil, Natural Gas, and Natural Gas Liquids Reserves, Energy Information Administration, DOE/EIA-0216(92).

U.S. Department of Energy. 1992. Component Design Report - Basic Framework \& Onshore Lower 48 Conventional Oil and Gas Supply. Energy. Information Administration. Washington, DC. 